\title{
Nonlinear internal waves over New Jersey's continental shelf
}

\author{
E. L. Shroyer, ${ }^{1,2}$ J. N. Moum, ${ }^{1}$ and J. D. Nash ${ }^{1}$ \\ Received 12 April 2010; revised 12 October 2010; accepted 22 December 2010; published 23 March 2011.
}

[1] Ship and mooring data collected off the coast of New Jersey are used to describe the nonlinear internal wave (NLIW) field and the background oceanographic conditions that formed the waveguide on the shelf. The subinertial, inertial, and tidal circulation are described in detail, and the background fluid state is characterized using the coefficients of the extended Korteweg-de Vries equation. The utility of this type of analysis is demonstrated in description of an amplitude-limited, flat wave. NLIWs observed over most of the month had typical displacements of $-8 \mathrm{~m}$, but waves observed from 17-21 August were almost twice as large with displacements near $-15 \mathrm{~m}$. During most of the month, wave packets occurred irregularly at a fixed location, and often more than one packet was observed per $\mathrm{M}_{2}$ tidal period. In contrast, the arrival times of the large-amplitude wave groups observed over 17-21 August were more closely phased with the barotropic tide. The time span in which the largest NLIWs were observed corresponded to neap barotropic conditions, but when the shoreward baroclinic energy flux was elevated. During the time of large NLIWs, near-inertial waves were a dominate contributor to the internal motions on the shelf and apparently regulated wave formation, as destructive/constructive modulation of the $\mathrm{M}_{2}$ internal tide by the inertial wavefield at the shelf break corresponded to stronger/weaker NLIWs on the shelf.

Citation: Shroyer, E. L., J. N. Moum, and J. D. Nash (2011), Nonlinear internal waves over New Jersey's continental shelf, J. Geophys. Res., 116, C03022, doi:10.1029/2010JC006332.

\section{Introduction}

[2] Nonlinear internal waves (NLIWs) have been documented throughout the world's coastal regions [Jackson, 2004]. These waves are characterized by large isopycnal displacements and velocity [e.g., Osborne and Burch, 1980; Klymak et al., 2006], and they are often associated with intense mixing [Sandstrom and Oakey, 1994; Inall et al., 2000; MacKinnon and Gregg, 2003; Moum et al., 2003]. Accordingly, NLIWs may influence many aspects of the coastal environment from acoustic propagation [Ramp et al., 2003] to vertical fluxes of nutrients [Sandstrom and Elliott, 1984]. NLIWs are regularly observed in satellite-based imagery and aerial photography, as both near-surface depression waves and bottom-trapped elevation waves possess surface signatures composed of alternating bands of rough and smooth water [e.g., Apel et al., 1975; Alpers, 1985; Gasparovic et al., 1988; Liu et al., 1998]. Due to the inherent variability of tidal forcing, mesoscale oceanic conditions, and the geometry of individual geographic regions, observed NLIW fields differ significantly from one another.

[3] Many NLIW observational studies have been conducted in marginal seas and other coastal regions that are

\footnotetext{
${ }^{1}$ College of Oceanic and Atmospheric Sciences, Oregon State University, Corvallis, Oregon, USA.

${ }^{2}$ Now at Woods Hole Oceanographic Institution, Woods Hole, Massachusetts, USA.

Copyright 2011 by the American Geophysical Union. 0148-0227/11/2010JC006332
}

partially isolated from the open ocean, e.g., in the Andaman Sea [Perry and Schimke, 1965; Osborne and Burch, 1980], the Sulu Sea [Apel et al., 1985], the South China Sea [Orr and Mignerey, 2003; Duda et al., 2004; Liu et al., 2004; Ramp et al., 2004], and Massachusetts Bay [Haury et al., 1979; Chereskin, 1983; Scotti et al., 2007]. In most cases, the generation of NLIWs in these partially enclosed regions is linked to barotropic tidal interaction with topographic sills or banks along their borders. Consequently, waves in these regions are often phased with the barotropic tide, allowing for rough predictions of arrival times at a given location [e.g., Ramp et al., 2004]. Apart from the proposed dependence on tidal motions, the details of the generation mechanism remain elusive. Two prominent possibilities include (1) the steepening and subsequent dispersion of a disturbance of the pycnocline that forms over a topographic feature during ebb flow [e.g., Scotti et al., 2007] and (2) scattering of an internal tidal beam off a moderately strong pycnocline [Gerkema, 2001]. The second mechanism is likely to be important when NLIWs first emerge at a large distance from local topography, for example in the Bay of Biscay [New and Pingree, 1992].

[4] Similar to NLIWs observed in partially enclosed bays and seas, the formation of waves in open shelf areas has also been attributed to either barotropic or baroclinic tidal interaction with the shelf break. However, observations have shown that the arrival times of these open-shelf waves are not necessarily phase-locked with the barotropic tidal cycle [e.g., Jeans and Sherwin, 2001; Moum et al., 2007; Moum 
and Nash, 2008]. Differences in wave arrival times in relation to the tide may be a consequence of multiple generation sites, subtidal changes in stratification, or advection by tidal, wind, and mesoscale currents. Changes in background stratification influence the NLIW field not only via direct control on the wave speed, but also through control on the conversion of the barotropic-to-baroclinic tide, which depends on the topographic slope, barotropic forcing, and the near-bottom stratification. In addition, stratification may effect the slope of internal tidal beams thus influencing the amount of internal tidal energy that is fluxed onto the shelf versus being reflected off of the slope into the deep ocean. Background currents influence both the advection of NLIWs and the evolution of the linear internal tide and its breakdown into higher-frequency NLIWs [e.g., Colosi et al., 2001]. Complicating matters further is the fact that NLIWs on continental shelves may be attributed to either a locally generated internal tide, remotely generated internal tide [e.g., Small et al., 1999], or some combination of the two.

[5] In light of the above considerations, it is perhaps not surprising that the observations presented here, which were collected as part of the Office of Naval Research's NonLinear Internal Wave Initiative/Shallow Water '06 Experiment (NLIWI/SW06) over the New Jersey shelf [Tang et al., 2007], show a diverse NLIW field. As part of this experiment, a shipboard survey of the NLIW field was performed from the R/V Oceanus during August 2006. The observed waves were primarily mode 1 depression waves propagating shoreward; however, the characteristic amplitudes of these waves varied by a factor of 2 over the course of the month. In addition, the arrival times of the observed waves were irregular with respect to the $\mathrm{M}_{2}$ barotropic tide. Departures from the norm also included the transition to elevation waves in three different wave groups that were tracked far inshore [Shroyer et al., 2009], as well as observations of mode 2 NLIWs [Shroyer et al., 2010a] and wave groups that propagated parallel to the shoreline.

[6] Here, we present a description of the general properties of the observed waves and characterize the background fluid state that controlled wave formation and shoaling. We begin by offering a brief description of the relevant experimental details (section 2). In section 3, the mesoscale, tidal, and inertial climates are described, and the influence of the background state on the NLIWs is explored using the coefficients of the extended Korteweg-de Vries (eKdV) equation. General properties of the observed nonlinear internal waves are summarized in section 4; a specific case study of a highly nonlinear wave group is also presented in this section. Aspects of NLIW formation are discussed in section 5. A summary is given in section 6 .

\section{Experimental Details}

[7] The SW06 site and bathymetry are shown in Figure 1. The grey cloud encompasses transects made by the $\mathrm{R} / \mathrm{V}$ Oceanus during NLIW tracking. The ship was equipped with a $120 \mathrm{kHz}$ echosounder (for flow imaging), a sidemounted $1200 \mathrm{kHz}$ ADCP, and a hull-mounted $300 \mathrm{kHz}$ ADCP. Shipboard acoustics, $X$ band radar, and visual sightings were used to determine wave orientation and track waves in the direction of propagation. Wave groups were transited through at $3-4 \mathrm{~m} \mathrm{~s}^{-1}$ from the back to leading wave, here the ship was turned and held quasi-stationary as microstructure measurements were collected using the Chameleon profiler [Moum et al., 1995]. After profiling through the leading few waves of a group, the process was repeated. Observations of 27 different ship-tracked wave packets were collected in this manner over the month of August. Some of these wave groups were followed more than $30 \mathrm{~km}$ across the shelf, while others were profiled through at only one station.

[8] An array of 11 across-shelf, environmental moorings (SW 29, 30, 34, 37, 38, 40, 41, 42, 43, 47, 62) located along the main wave transect path (Figure 1, blue diamonds) were used to define the background environmental conditions and wave evolution as they offer significant water column coverage of either density or velocity measurements. The moorings were of two types: water column and bottom landers; instrumentation on these moorings is summarized in Table 1. Note that all across-shelf distances are defined according to the axes shown in Figure 1, with the origin located at the mooring array intersection (SW30) and offshore velocities $>0$. The alongshore (across-shore) axis is rotated $30^{\circ}$ clockwise from north (east).

\section{Background Conditions}

[9] Shelf water in the Mid Atlantic Bight has origins extending from the Scotian Shelf and local river input [Chapman et al., 1986]. In the winter, this relatively cool, fresh water is further cooled at the surface and then mixed by tides and storms into a near-homogeneous "pool" on the shelf. In contrast, slope water is warm and salty, resulting in the establishment of a shelf-break front and a equatorward jet with mean transport of approximately $0.2 \mathrm{~Sv}$ off the New Jersey coast [Linder and Gawarkiewicz, 1998]. In summer, heating and freshwater runoff often obscure the surface signature of the front; however, temperature-salinity sections reveal its presence at depth beneath the seasonal, stratified mixed layer [Fratantoni et al., 2001; Linder and Gawarkiewicz, 1998]. Thus, during summer, the stratification on the shelf is supportive of internal waves, and NLIWs are commonly observed in this region during this time. Mesoscale variability associated with the front and jet may have a profound effect on the generation of the local internal tide, its subsequent steepening, and release of nonlinear internal waves. Below we document the subinertial and tidal circulation recorded during the SW06 experiment.

\subsection{Subinertial Circulation}

[10] Winds were initially weak (1-11 August 2006) before increasing in magnitude toward the southwest (11-16 August 2006). Afterward, northeastward winds persisted through the remainder of the month (Figure 2a). The shipboard tracking experiment began during the neap tide and continued through the following spring and neap tidal cycles (Figure 2b). The average mooring temperature field interpolated across the shelf (Figure 2c) reveals the subsurface signature of the shelf-break front, highlighted by the $12.5^{\circ} \mathrm{C}$ isotherm. Monthlong mean currents (de-tided) were primarily alongshore to the south with an estimated transport around $0.3 \mathrm{~Sv}$ (Figure 2d). Hence, the long-term mean circulation was perpendicular to onshore wave propagation. 


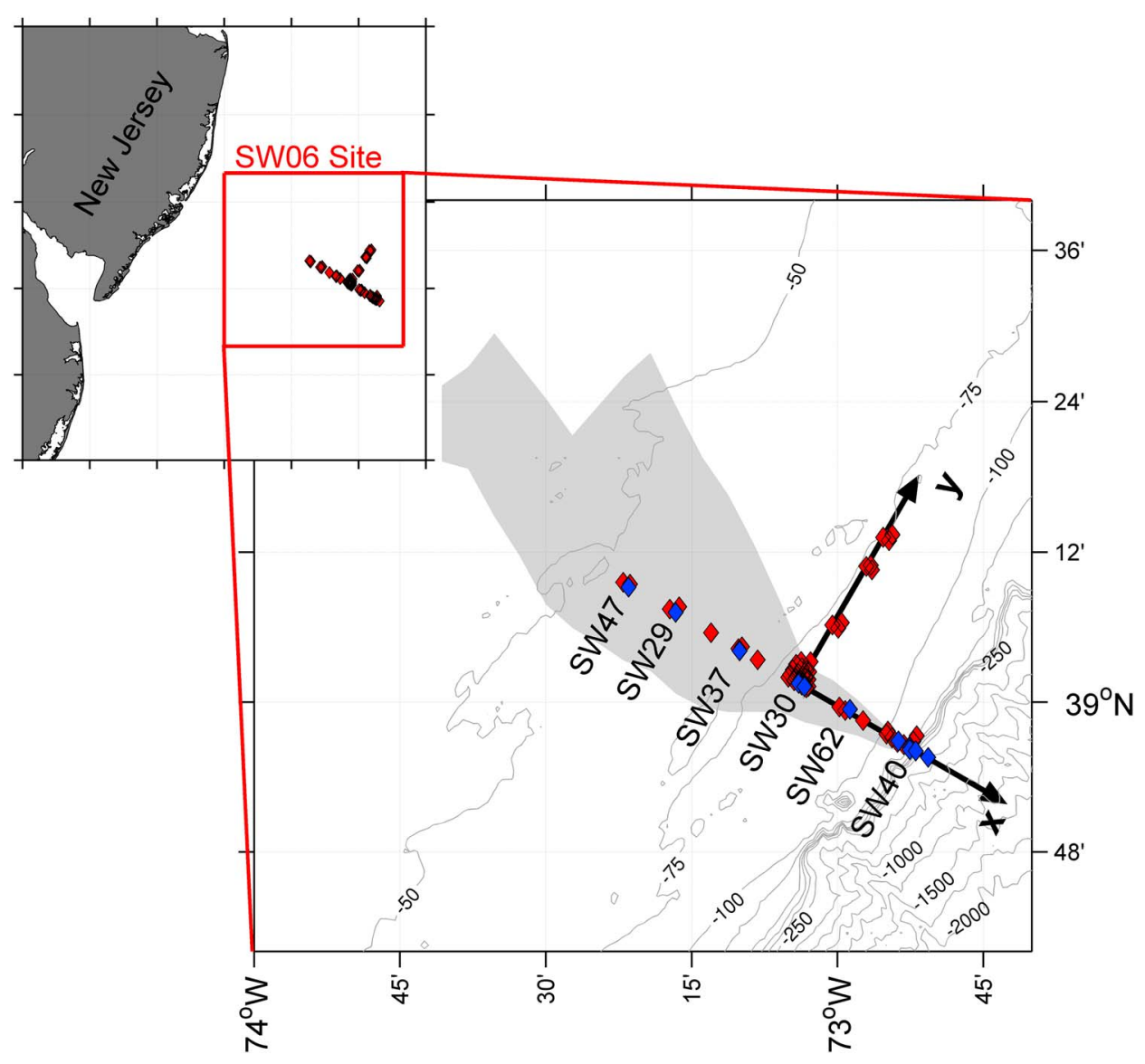

Figure 1. Site bathymetry, mooring locations (diamonds), and ship transect boundary (grey cloud). Blue diamonds show environmental moorings used in this analysis. For ease of viewing, only environmental moorings separated by large distances are labeled. Isobaths less than $250 \mathrm{~m}$ depth are plotted every $25 \mathrm{~m}$, and isobaths greater than this depth are plotted every $250 \mathrm{~m}$.

Mooring temperature, salinity, and density data on the slope were averaged over three different time periods (vertical dashed lines Figures $2 \mathrm{a}$ and $2 \mathrm{~b}$ ) qualitatively chosen by the character of the barotropic tide and observed internal wave properties (discussed in section 4). Each time period displayed a character change in the slope water, as the subsurface cool, fresh shelf water was shifted farther offshore during downwelling winds, and warm, salty slope water moved farther onshore with the onset of upwelling (Figures $2 \mathrm{e}-2 \mathrm{~g}$ ). Note, however, that dynamics other than those driven by the wind may be influencing the location of the front, e.g., frontal meanders.

[11] The regime shift is apparent in the temperature structure at both offshore and inshore moorings (Figures 3a and $3 b$ ). At the offshore mooring (Figure $3 b$ ), colder water was observed at the uppermost thermistor $(20 \mathrm{~m}$ depth) after 11 August 2006 as the shelf-break front presumably moved offshore. The temperature increased after 15 August 2006 as the front returned shoreward. Another difference is the temperature inversion at $\sim 75 \mathrm{~m}$ that was present intermittently during the first half of the record but absent between 15-25 August 2006. The signal at the inshore mooring is primarily tidal; however, a clear regime shift is apparent at roughly these same times (Figures $3 \mathrm{a}$ and $3 \mathrm{c}$ ) with the largest tidal displacements occurring after 16 August 2006.
[12] A 6 day running harmonic fit was used to characterize the across-shelf baroclinic circulation (Appendix A and Figure 4). Higher-frequency components are discussed in section 3.2; here, a few noteworthy features of the mean (corresponding to roughly a low-pass filter at 10 days) baroclinic field, $u_{0}$, are mentioned. $u_{0}$ was roughly coherent over at least a $10 \mathrm{~km}$ scale on the shelf, but this lowfrequency component differed at the slope moorings (Figure $4 \mathrm{~b}$ ). For example, $u_{0}$ near $15 \mathrm{~m}$ depth on 11 August 2006 was of a different sign on the shelf compared to the slope. In the shelf records, the flow was onshore (blue), but on the slope $u_{0}$ was directed offshore, suggesting a divergence of velocity somewhere in between SW38 and SW42. The opposite was true at the end of the month when there was a convergence in $u_{0}$ between the shelf and slope. In contrast to the trend noted by Colosi et al. [2001], these data do not show an obvious correlation between the direction of the barotropic component of $u_{0}^{B T}$ and the amplitude of the NLIWs (Figure 4b, inset).

\subsection{Inertial and Tidal Circulation}

[13] The time scales associated with inertial and tidal $\left(\mathrm{M}_{2}\right.$ and $\mathrm{K}_{1}$ ) motions are long compared to NLIWs, and these motions may therefore influence wave propagation through modulation of the background fluid. The $\mathrm{M}_{2}$ barotropic tidal 
Table 1. Summary of Moored Sensors Used in This Work

\begin{tabular}{|c|c|c|c|c|}
\hline Mooring & Type & Depth (m) & Distance $(\mathrm{km})$ & Location \\
\hline SW29 & $\begin{array}{l}\text { water column } \\
\text { temperature } \\
\text { conductivity } \\
\text { ADCP } \\
\text { tide gauge }\end{array}$ & $\begin{array}{c}62.5 \\
1,12,21,31,42,55,60 \\
12,31,55 \\
55 \\
55\end{array}$ & -21 & $39^{\circ} 7.2^{\prime}, 73^{\circ} 16.6^{\prime}$ \\
\hline SW30 & $\begin{array}{l}\text { water column } \\
\text { temperature } \\
\text { conductivity } \\
\text { ADCP }\end{array}$ & $\begin{array}{c}82 \\
14,17,21,26,33,40,48,57,66,75,83.3 \\
14,17,21,26,33,40,48,57,66,75 \\
75\end{array}$ & 0 & $39^{\circ} 1.5^{\prime}, 73^{\circ} 4.0^{\prime}$ \\
\hline SW34 & $\begin{array}{l}\text { water column } \\
\text { temperature } \\
\text { conductivity }\end{array}$ & $\begin{array}{c}124 \\
1,12,21,31,42,53,64,75,86,97 \\
106,118,121.5 \\
12,31,53,75,97,118\end{array}$ & 19 & $38^{\circ} 56.4^{\prime}, 72^{\circ} 52.6^{\prime}$ \\
\hline SW37 & $\begin{array}{l}\text { bottom lander } \\
\text { temperature/ } \\
\text { conductivity } \\
\text { pressure } \\
\text { ADP }\end{array}$ & 72 & -10 & $39^{\circ} 4.1^{\prime}, 73^{\circ} 10.1^{\prime}$ \\
\hline SW38 & $\begin{array}{l}\text { bottom lander } \\
\text { temperature/ } \\
\text { conductivity } \\
\text { pressure } \\
\text { ADCP }\end{array}$ & 79 & 1 & $39^{\circ} 1.2^{\prime}, 73^{\circ} 3.4^{\prime}$ \\
\hline SW40 & $\begin{array}{l}\text { bottom lander } \\
\text { temperature/ } \\
\text { conductivity } \\
\text { ADCP }\end{array}$ & 127.5 & 19 & $38^{\circ} 56.2^{\prime}, 72^{\circ} 52.6^{\prime}$ \\
\hline SW41 & $\begin{array}{l}\text { water column } \\
\text { temperature } \\
\text { conductivity }\end{array}$ & $\begin{array}{c}114 \\
11,16,22,30,39,48,59,70,81,93,105 \\
16,30,48,70,93\end{array}$ & 17 & $38^{\circ} 56.9^{\prime}, 72^{\circ} 53.7^{\prime}$ \\
\hline SW42 & $\begin{array}{l}\text { water column } \\
\text { temperature } \\
\text { conductivity } \\
\text { ADCP }\end{array}$ & $\begin{array}{c}175 \\
11,19,30,42,56,72,89,108,128,149,170 \\
19,42,72,108,149 \\
42,149\end{array}$ & 20 & $38^{\circ} 56.1^{\prime}, 72^{\circ} 52.0^{\prime}$ \\
\hline SW43 & $\begin{array}{l}\text { water column } \\
\text { temperature }\end{array}$ & $\begin{array}{c}480 \\
22.5,31.5,41.5,51.5,66.5,89.5,112.5 \\
140.5,169.5,199.5,230.5,262.5,295.5 \\
329.5,364.5,399.5,435.5,472.5 \\
31.5,41.5,66.5,112.5,169.5,230.5 \\
295.5,364.5,435.5 \\
52,435.5\end{array}$ & 22 & $38^{\circ} 55.6^{\prime}, 72^{\circ} 50.7^{\prime}$ \\
\hline SW47 & $\begin{array}{l}\text { water column } \\
\text { temperature }\end{array}$ & $1,14,20,25,30,35,40,55.5$ & -29 & $39^{\circ} 9.2^{\prime}, 73^{\circ} 21.5^{\prime}$ \\
\hline SW62 & $\begin{array}{l}\text { bottom lander } \\
\text { ADCP }\end{array}$ & 85 & 7 & $38^{\circ} 59.4^{\prime}, 72^{\circ} 58.7^{\prime}$ \\
\hline
\end{tabular}

ellipses are oriented across isobaths with magnitudes near $10 \mathrm{~cm} \mathrm{~s}^{-1}$ on the shelf (Figure 4c). Both the magnitudes and directions agree well with historic data [Moody and Butman, 1984] and fits from the TPXO tidal model [Egbert et al., 1994]. The orientation and phase of $\mathrm{K}_{1}$ ellipses vary between the slope and the shelf (Figure $4 d$ ). Similar to $M_{2}$, $\mathrm{K}_{1}$ barotropic tidal ellipses on the slope are directed acrossisobath. For these moorings, $\mathrm{K}_{1}$ amplitudes are small (less than $1 \mathrm{~cm} \mathrm{~s}^{-1}$ ). On the shelf, $\mathrm{K}_{1}$ ellipses are oriented primarily in the along-isobath direction with amplitudes less than $5 \mathrm{~cm} \mathrm{~s}^{-1}$.

[14] The increase in magnitude near 16 August 2006 is one of the most striking features of the $\mathrm{M}_{2}$ baroclinic velocity records from moorings SW37, SW38, and SW42 (Figure 4c). Note that $u_{M 2}$ at SW43 increases in magnitude much earlier in the month (circa 11 August 2006) than at the other moorings. Considering the small distance between SW42 and SW43, this difference is perhaps surprising. However, SW43 was located on the slope (480 m water depth) and SW42 was located near the shelf break in shal- lower water. As such, the disparity in the records may be attributed to internal tidal energy fluxed onto the shelf versus that reflected off of the slope. The $\mathrm{K}_{1}$ tidal component was in general much weaker in magnitude (Figure $4 \mathrm{~d}$ ), which is to be expected since the latitude of the study site is north of that for which a freely propagating baroclinic wave of this periodicity is expected. We, therefore, do not explore $u_{K 1}$ in greater detail. The dominant pattern observed in the inertial record includes the near absence of a signal from 6-11 August 2006 and the increase in magnitude that occurred after this time span (Figure 4e). This signal is consistent with the increase in wind speed measured after 11 August. Both low- (e.g., note the roughly 2 day signal in the lower layer) and high-frequency modulations are evident in the residual, $u_{r}$ (Figure 4f).

[15] On the shelf, the baroclinic $\mathrm{M}_{2}$ and inertial acrossshelf velocity components were mode 1 in vertical structure (Figures $4 \mathrm{c}-4 \mathrm{e}$ and Figure $5 \mathrm{a}$ ), each with zero crossing near $30 \mathrm{~m}$ depth (between 0.35-0.40H). On the slope, the $\mathrm{M}_{2}$ baroclinic tide was also primarily mode 1 at SW43; 

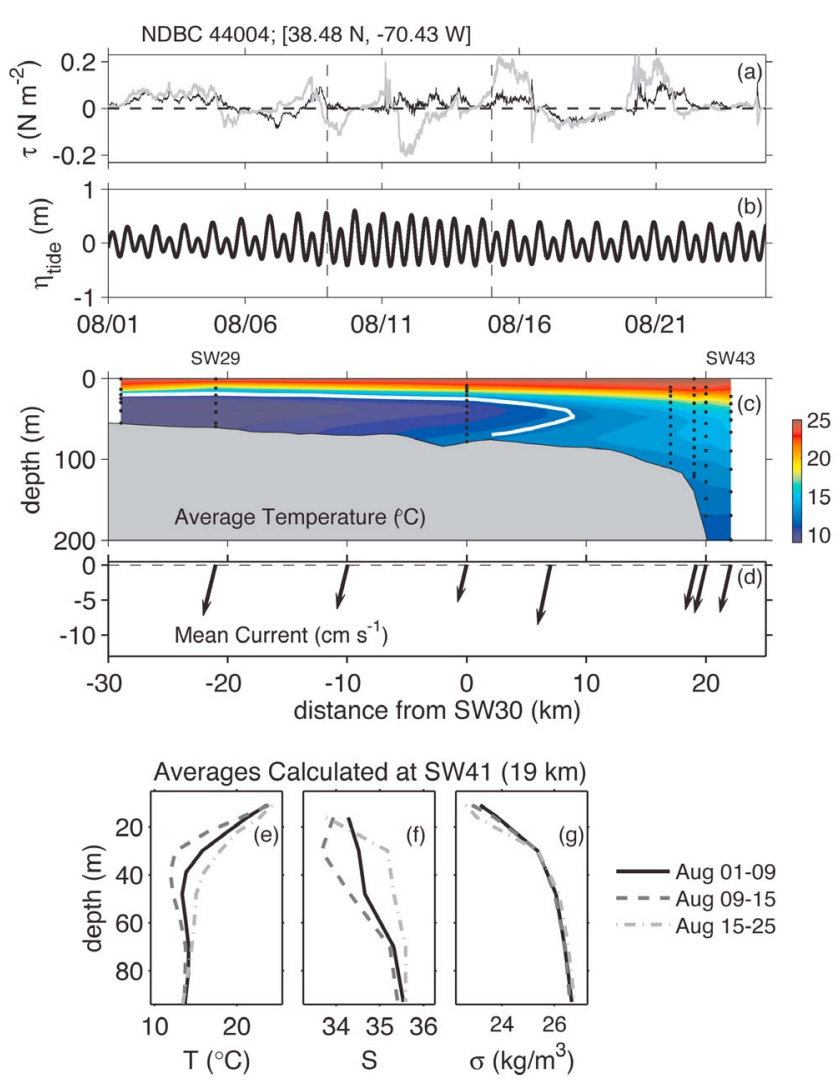

Figure 2. (a) Across- and along-shore wind stress (black/ grey) from NDBC buoy $44004\left(38^{\circ} 29^{\prime} \mathrm{N}, 70^{\circ} 26^{\prime} \mathrm{W}\right)$. (b) Tidal height computed from a bottom-pressure sensor on mooring SW38 $(1 \mathrm{~km})$. (c) Average across-shelf temperature during the month of August. The $12.5^{\circ} \mathrm{C}$ isotherm is shown in white. Actual mooring locations are at $[22,20$, $19,17,0,-21,-29] \mathrm{km}$; temperature sensor depths are indicated by black dots. (d) De-tided mean current over the month of August. Arrow locations show positions of moorings equipped with acoustic Doppler profilers with the exception of SW38. Time averages of (e) temperature, (f) salinity, and (g) density for periods separated by vertical dashed lines in Figures $2 \mathrm{a}$ and $2 \mathrm{~b}$. the zero crossing at this slope mooring is located near $180 \mathrm{~m}(0.38 H)$. The baroclinic inertial signal in the upper $60 \mathrm{~m}$ was similar at all shelf and slope moorings, suggesting the inertial input was relatively constant in space over the span of the array (Figure 4e). While on the slope the vertical structure of the inertial signal had multiple zero crossings in the deeper part of the water column, the sole crossing above $150 \mathrm{~m}$ occurred near $30 \mathrm{~m}(.07 \mathrm{H}$; Figure $5 \mathrm{~b})$.

[16] To quantify the relative importance of inertial and $\mathrm{M}_{2}$ motions, the total KE in these bands was calculated at a shelf and slope mooring (Figures $5 \mathrm{c}$ and $5 \mathrm{~d}$ ). On the shelf, the $K E$ in the inertial band was roughly 2-4 times larger than the $\mathrm{M}_{2}$ energy over the latter part of the month. From 6 to 11 August, $K E$ in both bands was weak and near the same magnitude. The increase in the $\mathrm{M}_{2}$ component, which peaked on 18 August, coincided with the arrival of largeramplitude NLIWs (as shown by the increased power at frequencies near $10^{-3} \mathrm{~s}^{-1}$ (Figure 3c)) but was not directly proportional to the barotropic forcing (Figure $2 b$ and grey line in Figure 5c). In contrast to shelf conditions, the $\mathrm{M}_{2}$ energy was roughly twice as large as the inertial energy on the slope. The increase in $\mathrm{M}_{2} K E$ occurred near 12 August, in phase with barotropic forcing at the slope mooring (grey line, Figure 5d).

[17] Summarizing the above in a context relevant to the NLIWs, the observed variability in the mesoscale conditions was likely attributed to the offshore/onshore "wandering" of the shelf-break front and jet. The energy in the $M_{2}$ baroclinic tide and the NLIW field increased at roughly the same time as a major shift in mesoscale conditions occurred. Inertial waves and the $\mathrm{M}_{2}$ baroclinic tide were both primary contributors to motions across the shelf. The internal tide was highly irregular with considerable energy spread across semidiurnal harmonics (e.g., see the $\mathrm{M}_{4}$ band marked Figure 3c). The energy associated with these higherfrequency motions is not explicitly accounted for in the harmonic fit and thus appears in the velocity residual (Figure $4 \mathrm{f}$ ). The variability of these internal motions (both subinertial and superinertial) undoubtedly contributed to the sporadic nature of NLIW arrivals at a given location (section 4). Note that although the shift in the stratification at the shelf break is conducive to allowing a larger flux of

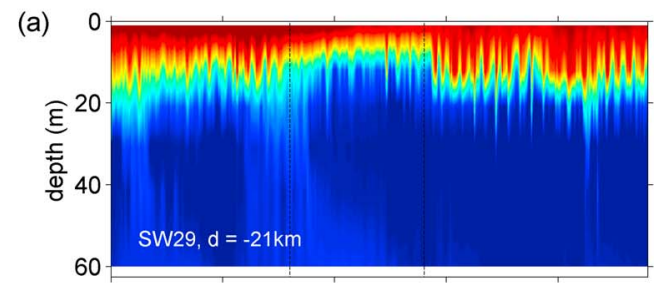

(b)

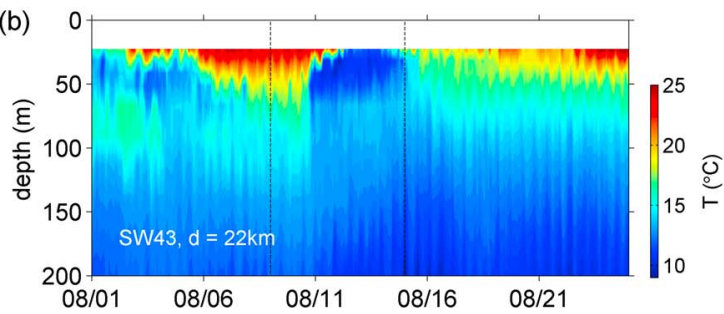

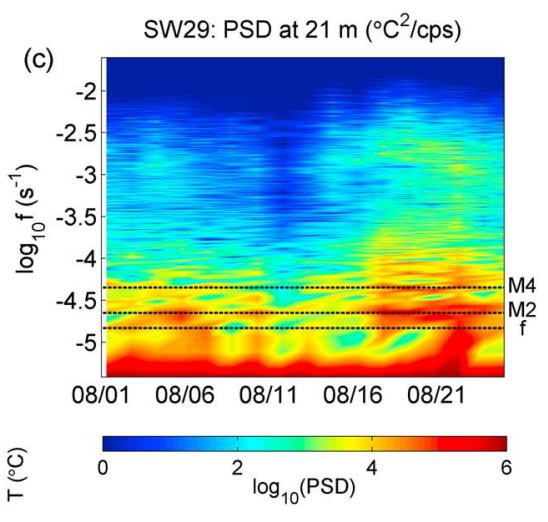

(25)

Figure 3. Temperature in $1 \mathrm{~h}$ bins at an (a) inshore mooring and (b) offshore mooring. (c) Spectrogram of temperature at $21 \mathrm{~m}$ depth at the inshore mooring (SW29). 

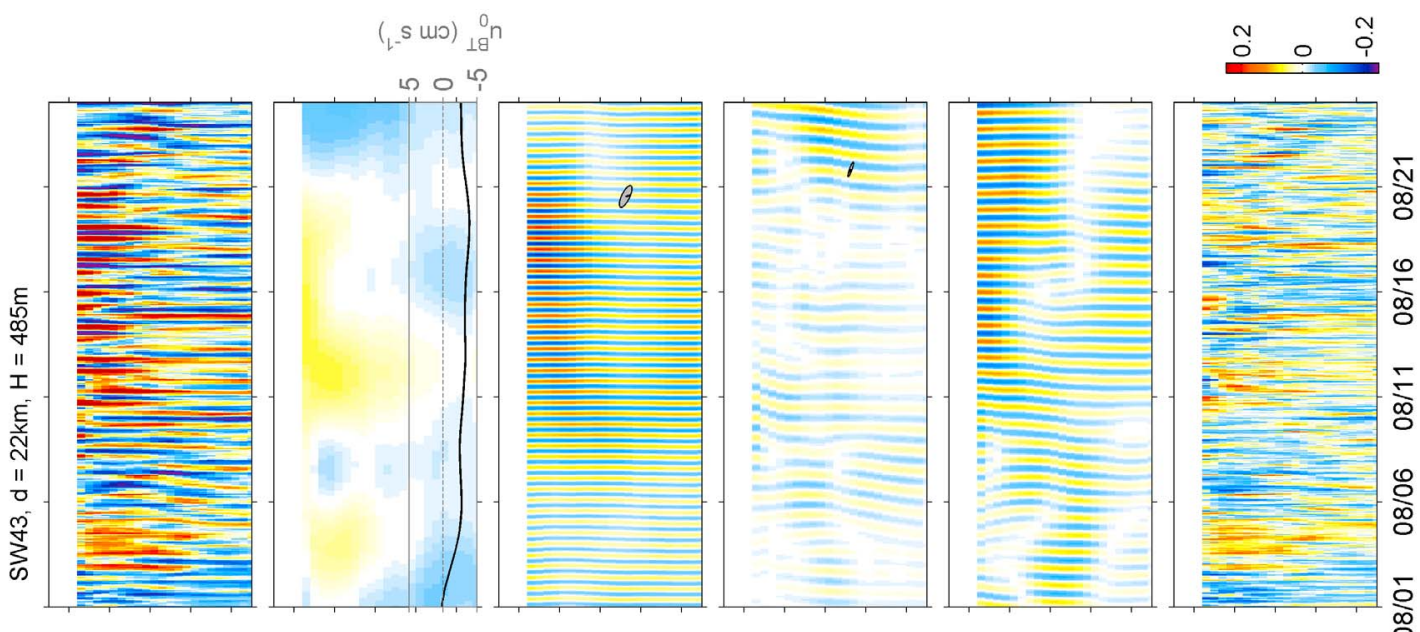

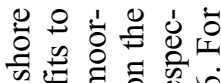

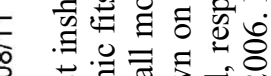

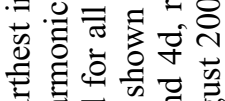

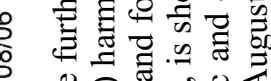

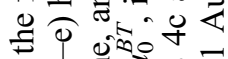

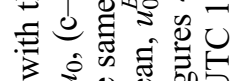
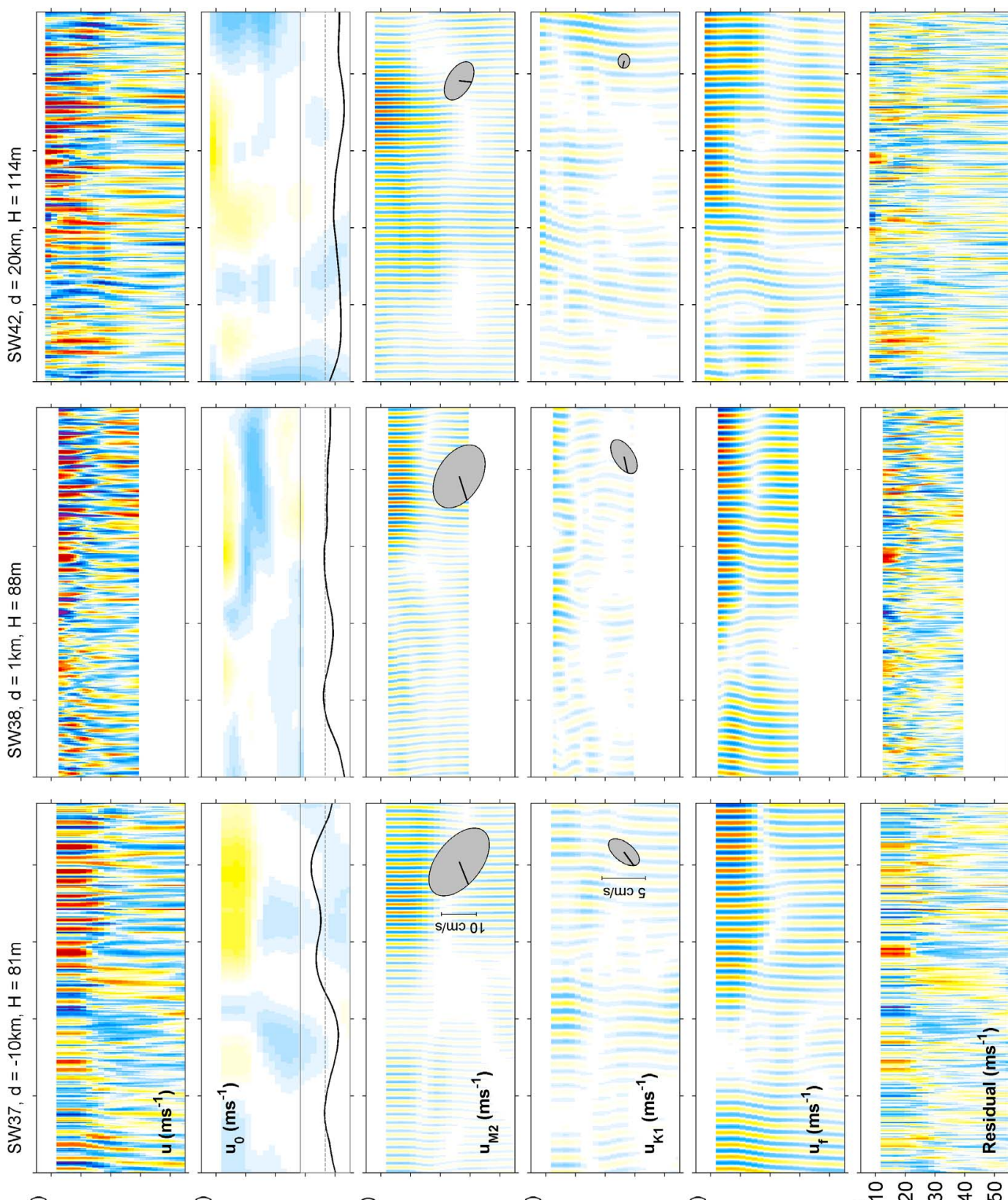

a

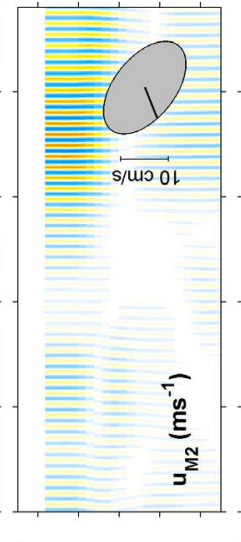

(อ)

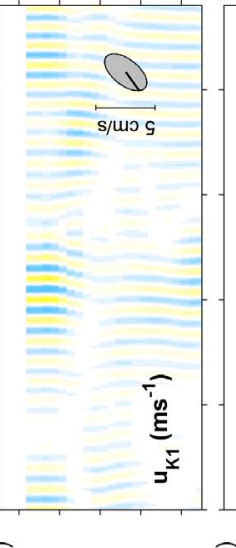

e

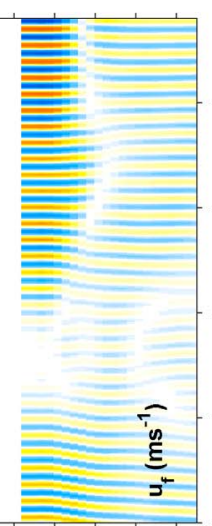

$\widehat{\Theta}$

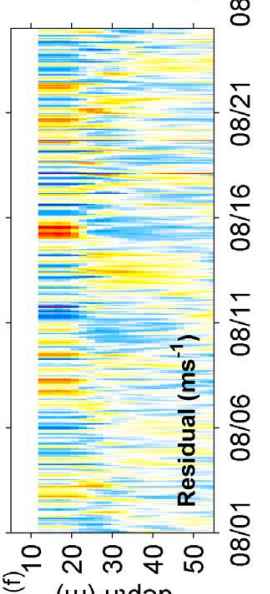

(u) uldəp

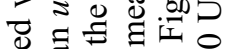


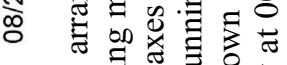

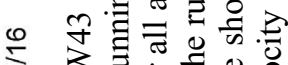

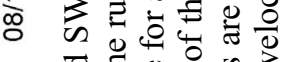

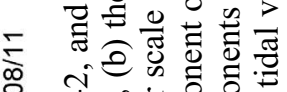

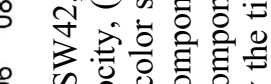
$\because$ in 0 : 000

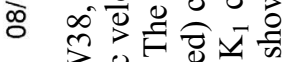

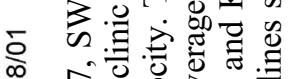

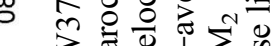
- की ๙ $\circ$ क्ष由

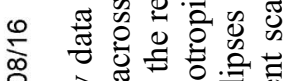

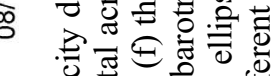
₹ . $\circ:$ ङ o

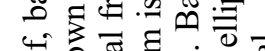

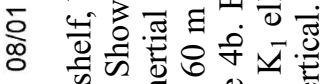

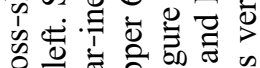

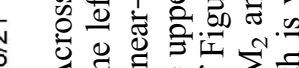

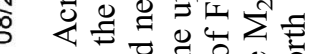

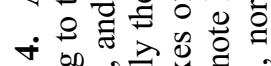

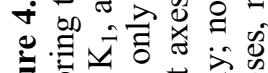

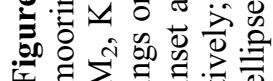


(a) SW37 at $-10 \mathrm{~km}, \mathrm{H}=81 \mathrm{~m}$

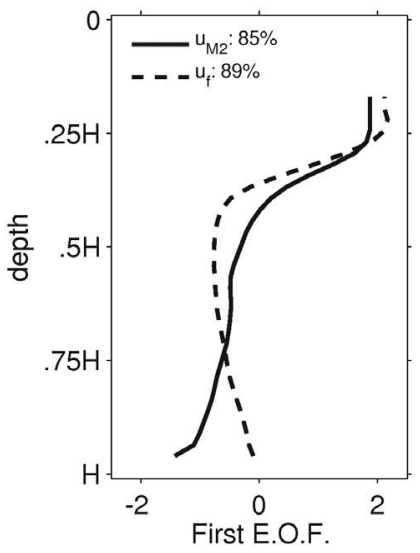

(b) SW43 at $22 \mathrm{~km}, \mathrm{H}=485 \mathrm{~m}$

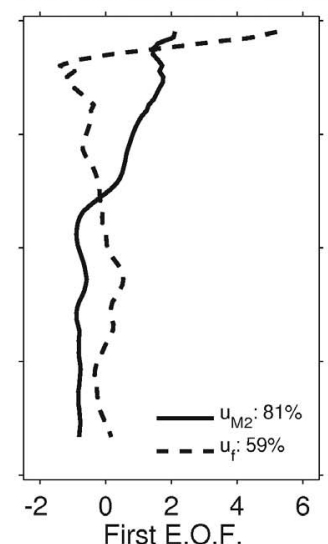

(c)

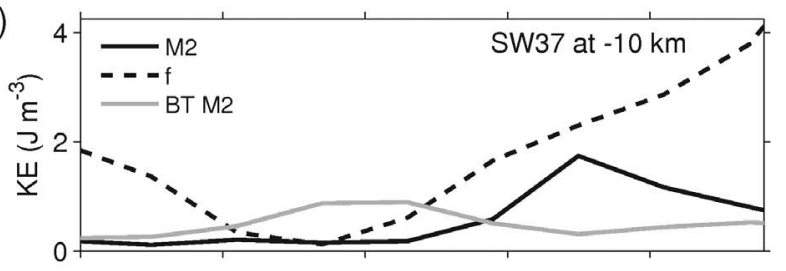

(d)

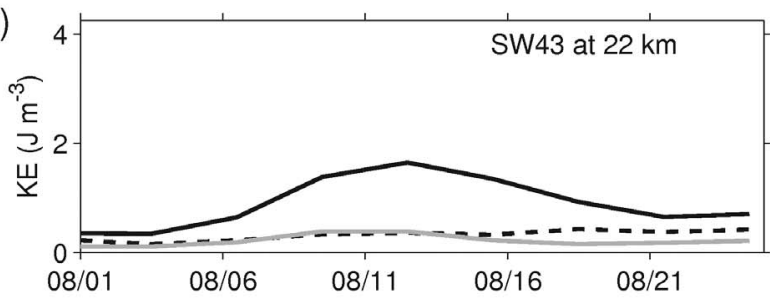

Figure 5. First E.O.F. calculated for the harmonic fits, $u_{f}$ and $u_{M 2}$, on (a) the shelf and (b) the slope. Three day averages of the kinetic energy in the $\mathrm{M}_{2}$ and near-inertial baroclinic fields at a (c) shelf and (d) slope mooring. Solid grey lines show the barotropic (depth-averaged) $\mathrm{M}_{2}$ velocity. In Figure 5c, the barotropic KE has been decreased by a factor of 10 for scale purposes.

internal tidal energy onto the shelf, work by J. D. Nash et al. (The futility of predicting internal tides and nonlinear internal waves on the continental shelf, manuscript in preparation, 2011) suggests that the largest contribution to the variability in the $\mathrm{M}_{2}$ baroclinic tide is due to shoaling of remotely generated waves.

\subsection{Properties of the Waveguide}

[18] The effect of the background density and velocity structure on NLIW evolution may be quantified using the coefficients of the eKdV equation for the isopycnal displacement, $\eta$,

$$
\frac{\partial \eta}{\partial t}+\left(c_{0}+\alpha \eta+\alpha_{1} \eta^{2}\right) \frac{\partial \eta}{\partial x}+\beta \frac{\partial^{3} \eta}{\partial x^{3}}=0 .
$$

Figures $6 \mathrm{a}-6 \mathrm{~d}$ show the coefficients governing dispersion $(\beta)$, second-order nonlinearity $\left(\alpha_{1}\right)$, and first-order nonlinearity $(\alpha)$, as well as the linear long wave speeds $\left(c_{0}\right)$ for all ship-tracked waves. These parameters depend on the back-

ground velocity, the linear vertical structure function, and a second-order correction to the vertical structure function. The values are not explicitly defined here; for a complete discussion of the eKdV equation refer to Grimshaw et al. [2004]. The reader will note that Figure 6 is essentially a reproduction of their Figures 3, 7, and 11 for the SW06 data.

[19] All coefficients were computed using background estimates of local density and shear from ship-based observations. Background density profiles, $\bar{\sigma}(z)$, were calculated using an average of microstructure profiles taken ahead of the waves (typically 2). Background velocity profiles, $\bar{u}(z)$, were calculated by averaging approximately 5-10 min of ADCP data ahead of the wave (oriented in the

(a)

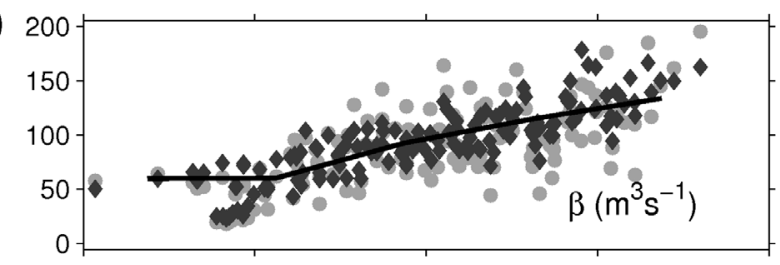

(b)

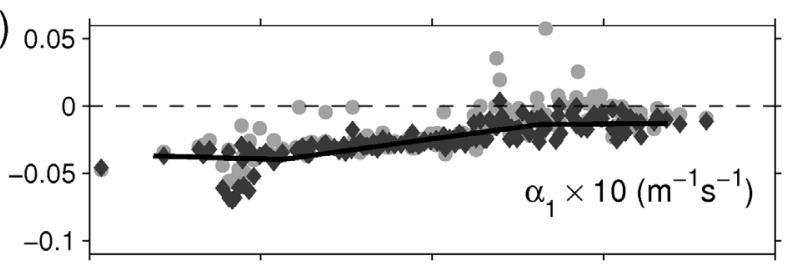

(c)

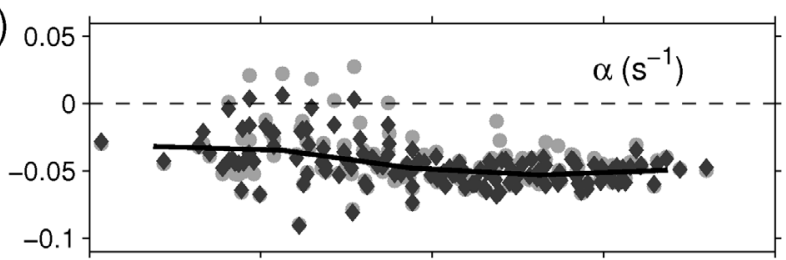

(d)

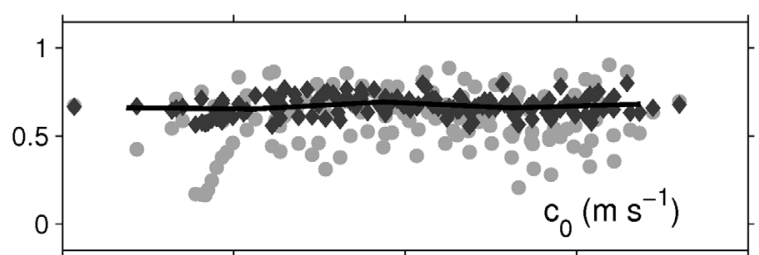

(e)

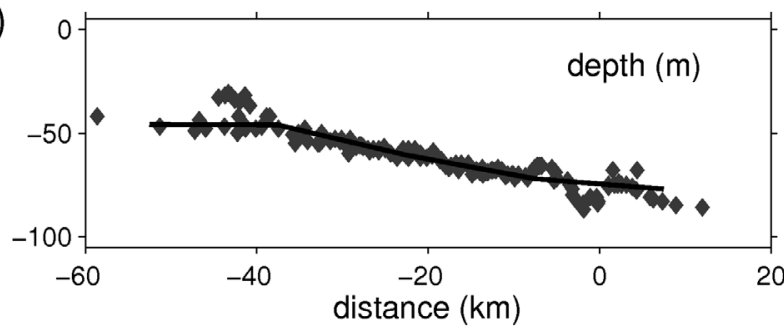

Figure 6. Summary showing values of the (a) dispersion coefficient, (b) second-order nonlinear coefficient, (c) firstorder nonlinear coefficient, (d) shoreward linear long wave speed, and (e) bottom depth ahead of each wave profiling series. Calculations were made with/without background shear (light grey circles/dark grey diamonds). Variations in $c_{0}$ calculated with the background velocity include advection by the barotropic, background flow. Black lines show $15 \mathrm{~km}$ bin averages of parameters calculated without shear. 

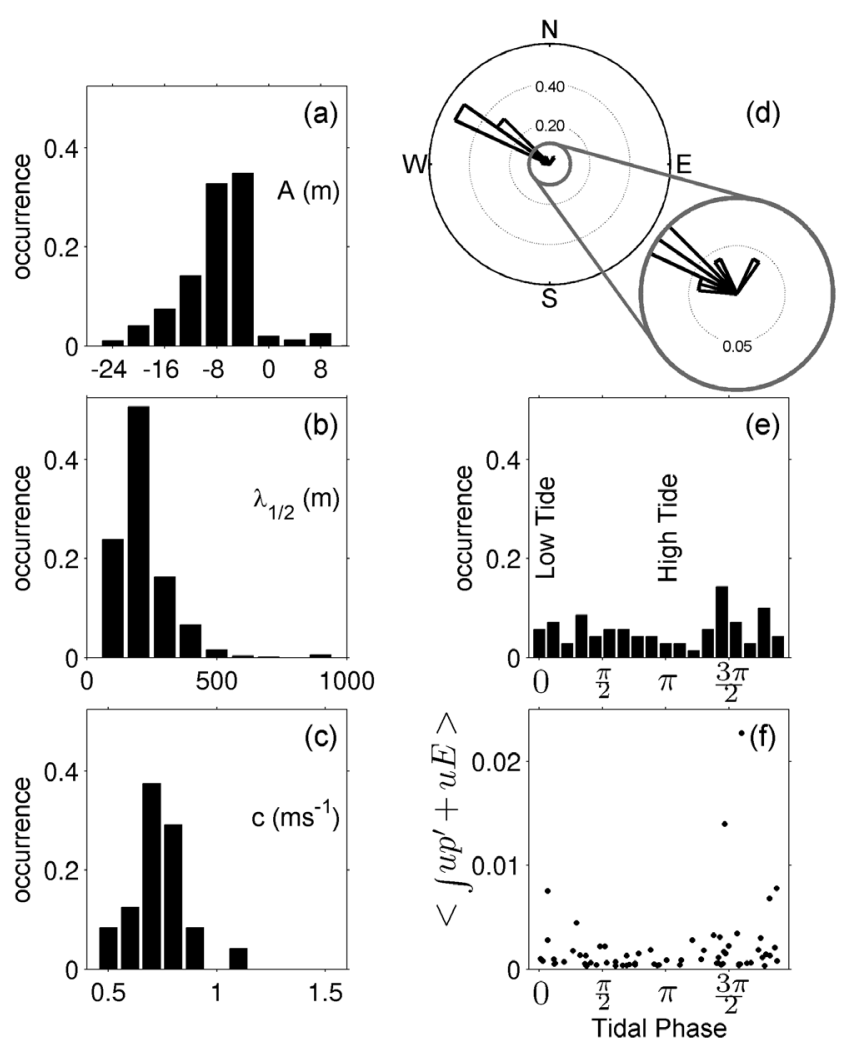

Figure 7. Histograms of (a) displacement amplitude, (b) half-width, (c) average shoreward wave speed, (d) wave heading, (e) wave arrival time at SW30 relative to the local barotropic $\mathrm{M}_{2}$ tidal height, and (f) average energy flux as a function of $\mathrm{M}_{2}$ tidal phase (low tide corresponds to zero). Figures $7 a-7 d$ were calculated from shipboard data; Figures $7 \mathrm{e}$ and $7 \mathrm{f}$ were calculated using mooring data from SW30.

direction of propagation); the exact value differed depending on the length of time between ship positioning and wave arrival. Both $\bar{\sigma}$ and $\bar{u}$ were low-pass filtered at $0.15 \mathrm{~m}^{-1}$ in the vertical.

[20] The magnitude of the dispersive term, $\beta$, decreased as the bottom depth shoaled (Figures 6a and 6e), while at the same time the magnitude of the second-order nonlinear term, $\alpha_{1}$, steadily increased (Figure $6 \mathrm{~b}$ ), so that in shallow water higher-order nonlinear effects were more important. Almost all values of $\alpha_{1}$ calculated without background shear (dark grey diamonds) are less than zero. Inclusion of background shear (light grey circles) yields some values of $\alpha_{1}$ that are greater than zero on the outer shelf. The calculation of $\alpha_{1}$ is sensitive to the background shear, and these positive values may be a consequence of the numerical calculation and the smoothness of $\bar{u}$.

[21] Inshore, $\alpha$ was greater than zero in localized regions (Figure 6c); these locations corresponded to times when elevation waves were observed [Shroyer et al., 2009]. The background shear in these locations served to "push" the system toward an elevation-friendly environment. Note that there is not a rigorous dependence of the sign of $\alpha$ on the across-shelf distance. That is, not all waves were observed to transition past a certain physical location; this is indica- tive of the large variability observed in background stratification and shear for each wave group. The spread apparent in the linear long wave speed (Figure 6d) further illustrates the diversity in the background velocity field. Note that advection by the larger-scale mean current is included in $c_{0}$.

[22] Small-scale, localized effects can have a strong control on the coefficients; as an example, the offshoot of low $c_{0}$ at $-42 \mathrm{~km}$ is associated with one wave group that encountered a topographic bump (Figure 6e). While the resulting wave dynamics are not discussed here, examination of $\alpha_{1}$ and $\beta$ indicates the dominance of higher-order nonlinearity over weak dispersion for this wave group. (See Shroyer et al. [2010b] for a more thorough analysis of this wave group.)

\section{Characteristics of NLIWs}

\subsection{Wave Properties}

[23] Observed displacement amplitudes $(A)$ of ship-tracked waves ranged from $-24 \mathrm{~m}$ to $10 \mathrm{~m}$ with a mean magnitude of $|A|=8 \mathrm{~m}$ (Figure 7a). $A$ is defined by the maximum isopycnal displacement and is positive/negative for elevation/depression waves. In this paper the term amplitude will be used when referring to the magnitude of $A$, and displacement will refer to both the sign and magnitude of $A$. The half-width $\left(\lambda_{1 / 2}\right)$, defined as the distance over which the amplitude decreased by half, ranged from a minimum of $80 \mathrm{~m}$ to over $900 \mathrm{~m}$ with a mean value of $230 \mathrm{~m}$ (Figure $7 \mathrm{~b}$ ). The mean value of the average wave speeds (c), calculated by differencing time and position, was approximately $0.78 \mathrm{~m} \mathrm{~s}^{-1}$ (Figure 7c). All but one of the ship-tracked wave groups propagated shoreward (compass heading 300), the exception propagated parallel to the shoreline, heading 010 (Figure 7d). Though Figure 7d was computed from shipboard data, measurements at SW30 $(0 \mathrm{~km})$ give a similar result with mean (over all observed waves) heading 310 (computed by minimizing the across-axis wave velocity component). Data from SW30 were used to compute Figures $7 \mathrm{e}$ and $7 \mathrm{f}$. Wave arrival times were not correlated with the local barotropic $\mathrm{M}_{2}$ tidal height (Figure 7e), with both large and small waves (distinguished using the average of the vertically integrated energy flux in wave packets) arriving at various stages of the barotropic tide (Figure 7f).

[24] Average wave speeds are shown in Figures 7c and 8b; however, wave speeds were not constant and were modulated by the background velocity. For wave groups that were tracked large distances across the shelf (in excess of $30 \mathrm{~km}$ ), the change in the phase speed from the wave's across-shelf mean speed, $\Delta c$, was significantly correlated with acrossshelf barotropic velocity; on average, there existed a one-toone relationship between $\Delta c$ and the barotropic velocity, confirming that waves were advected with the barotropic tide. Although not explored explicitly here, the baroclinic velocity field may have influenced other characteristics of the NLIWs, from the half-width length to the nature of the limiting amplitude [Stastna and Lamb, 2002].

[25] For bookkeeping purposes, ship-tracked waves were named following the convention used for tropical storms. Figure $8 \mathrm{c}$ gives the names of the various wave groups and their arrival time at $\mathrm{SW} 30\left(39^{\circ} 0^{\prime} \mathrm{N}, 73^{\circ} 1^{\prime} \mathrm{W}, 0 \mathrm{~km}\right)$, along with the arrival times of other mooring-observed NLIWs (closed markers). Ship-tracked wave groups were identified by using the sighting nearest SW30 and the average wave 


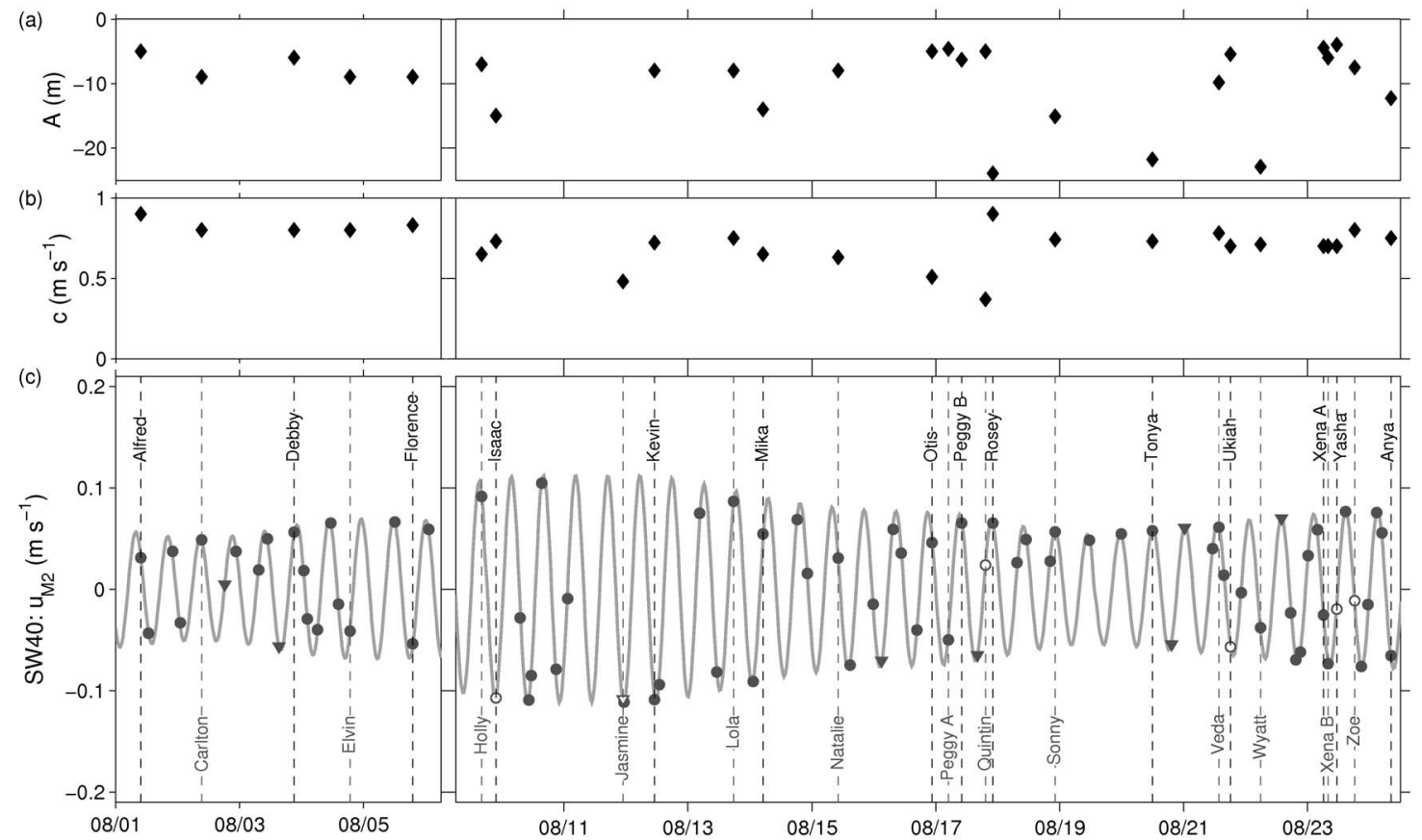

Figure 8. (a) Maximum magnitude of wave displacement amplitude and (b) average wave speed of shiptracked waves. (c) Barotropic $u_{M 2}$ at a shelf-break mooring (SW40) with arrival times at SW30 of mode-1 (circles) and mode-2 (triangles) NLIWs. Waves tracked from the ship are named. Open markers indicate ship-tracked waves that do not appear in the mooring record; for these six waves, arrival times are projections based on the closest observation point and the measured wave speed. The ship returned to port from the 6-9 August; since no waves were tracked during this period, it is excluded for aesthetic reasons.

speed to project wave arrival at the mooring either forward or backward in time. As previously mentioned, wave arrivals were not phase-locked with the barotropic $\mathrm{M}_{2}$ tide; the spread in arrival times hints at a complicated formation story. The period from 17-21 August is notable in that wave arrival times were roughly phased with the barotropic $M_{2}$ tidal current measured at SW40.

[26] Six ship-tracked wave groups do not appear in the SW30 mooring record; however, these waves are included in Figure 8 (open markers) using the projected arrival time. Of these six wave groups, Jasmine was a mode 2 wave that dissipated before reaching SW30. Another wave group, (Ukiah), propagated along the coast and was only observed inshore of SW30. Isaac was a relatively large amplitude wave that was first observed $40 \mathrm{~km}$ inshore of SW30. Failure to isolate this wave in the record may be associated with the difficulty in accurately predicting the arrival this far back in time (40 km corresponds to roughly $15 \mathrm{~h}$ ). The remaining three wave groups were all of small amplitude; these waves may have formed inshore of SW30 or possibly their signal was not sufficiently strong to be isolated in the mooring record due to poor resolution of both velocity and displacements near the surface.

[27] In the majority of observed wave groups, the maximum amplitude was close to the mean value of $|A|(8 \mathrm{~m})$, with a clear departure from this trend during the period between 1800 UTC 17 August 2006 and 0000 UTC 22 August 2006 (Figure 8). Over this time period, waves Rosey, Sonny, Tonya, and Wyatt had displacements in excess of $-15 \mathrm{~m}$. Surprisingly, these larger-amplitude waves were not asso- ciated with the spring tide, which has been linked to larger internal waves in other studies [e.g., New and Pingree, 1990; Ramp et al., 2004; Scotti et al., 2007]. The period of larger-amplitude NLIWs coincided with the change in stratification at the shelf break (Figure $2 \mathrm{f}$ and section 3 ), an increase in internal tide energy fluxed onto the shelf (Nash et al., manuscript in preparation, 2011), and the period of more uniform NLIW arrival times (Figure 8c).

\subsection{A Case Study: An Amplitude-Limited Wave Group}

[28] Here, we present detailed measurements of Wave Rosey, the largest wave group tracked from the ship. Mooring records indicate that this wave group was one of the largest observed during the entire experiment, and analysis of the eKdV coefficients indicate that Rosey reached the limiting amplitude predicted for its background fluid state. Despite the extreme amplitude observed in this wave, this example serves a more general purpose in that it highlights the influence of background conditions on NLIW structure.

[29] Depending on the stratification, background shear, and water column depth, one way in which nonlinear waves may be bounded in amplitude is such that increased energy input results in an increase in wavelength rather than further amplitude growth. As wavelength increases, a region of flat isopycnals develops at the wave's center. In this region, the velocity of the so-called "table" solitons, which have also been termed "thick" or "flat" solitons, is horizontally uniform and is referred to as the conjugate of the upstream flow 
(a)

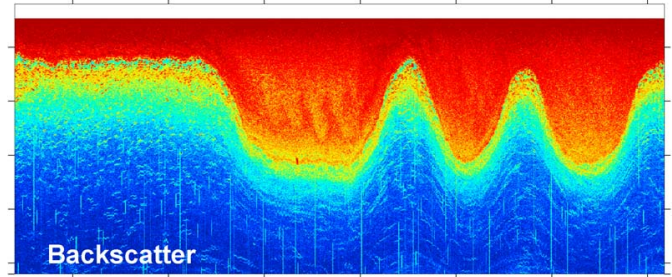

(b)

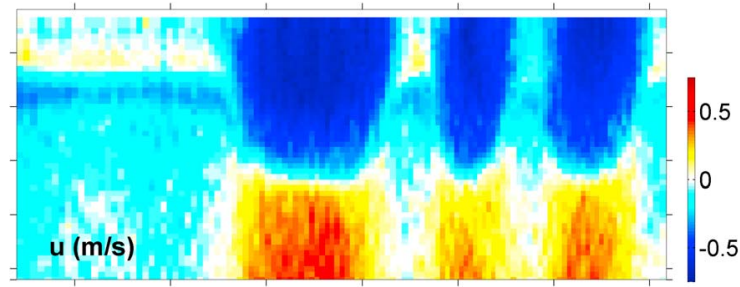

(c)

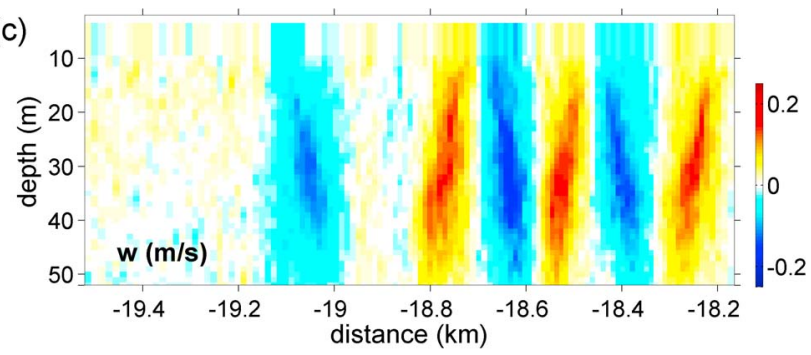

Figure 9. (a) Backscatter, (b) across-shelf velocity, and (c) vertical velocity for Wave Rosey at 0400 UTC 18 August 2006.
[Lamb and Wang, 1998]. High-resolution measurements from the ship reveal a unique shoaling story for Rosey, in which the leading wave became extremely wide when the measured amplitude was near the limiting amplitude.

[30] Inshore of $-7 \mathrm{~km}$, the leading wave grew in magnitude to over $20 \mathrm{~m}$ and took on a "squarish" character reminiscent of a table soliton (Figure 9). At this location horizontal velocities exceeded $0.75 \mathrm{~m} \mathrm{~s}^{-1}$ and vertical velocities reached $0.25 \mathrm{~m} \mathrm{~s}^{-1}$. The downward velocity pulse at the leading edge was separated by over $100 \mathrm{~m}$ from the upward return at the trailing edge of the wave, further emphasizing the square-like nature of the wave. Backscatter images across the shelf clearly show the increase in amplitude and wavelength of the leading wave (Figure 10b). Using the eKdV formulation, the weakly nonlinear (WNL) limiting amplitude was calculated as

$$
A_{\text {limit }}=-\frac{\alpha}{\alpha_{1}}
$$

[e.g., Grimshaw et al., 2004; Stanton and Ostrovsky, 1998]. Comparison of the measured displacement amplitude to the WNL limit shows that the two converged as Rosey traveled shoreward (Figure 10a), suggesting that the waveform approached the conjugate flow state between $\mathrm{x}=-10$ and $\mathrm{x}=-15 \mathrm{~km}$.

\section{Wave Formation}

\subsection{Steepening of the Internal Tide}

[31] As stated, wave arrival times at SW30 did not consistently and directly correspond to the barotropic,
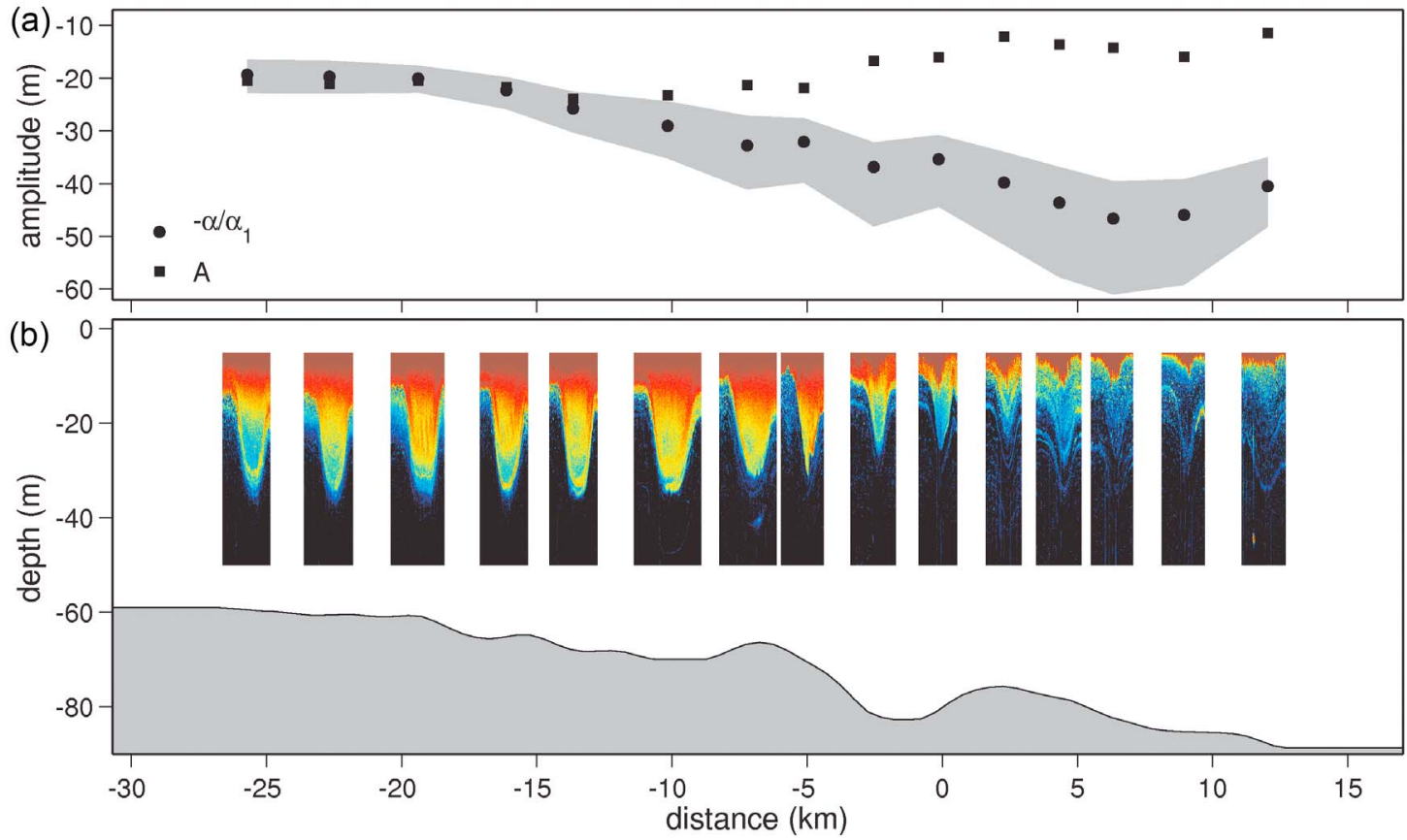

Figure 10. (a) Black circles show the limiting amplitude as defined by eKdV analysis. The grey cloud represents limits assuming the depth is known to within $\pm 2 \mathrm{~m}$. Black squares show the measured displacement amplitude of the leading wave. (b) Backscatter images of the leading wave plotted across topography. Images are centered at location of observations. Depths are true to the vertical axis, but wavelengths have been increased by a factor of 3 . 

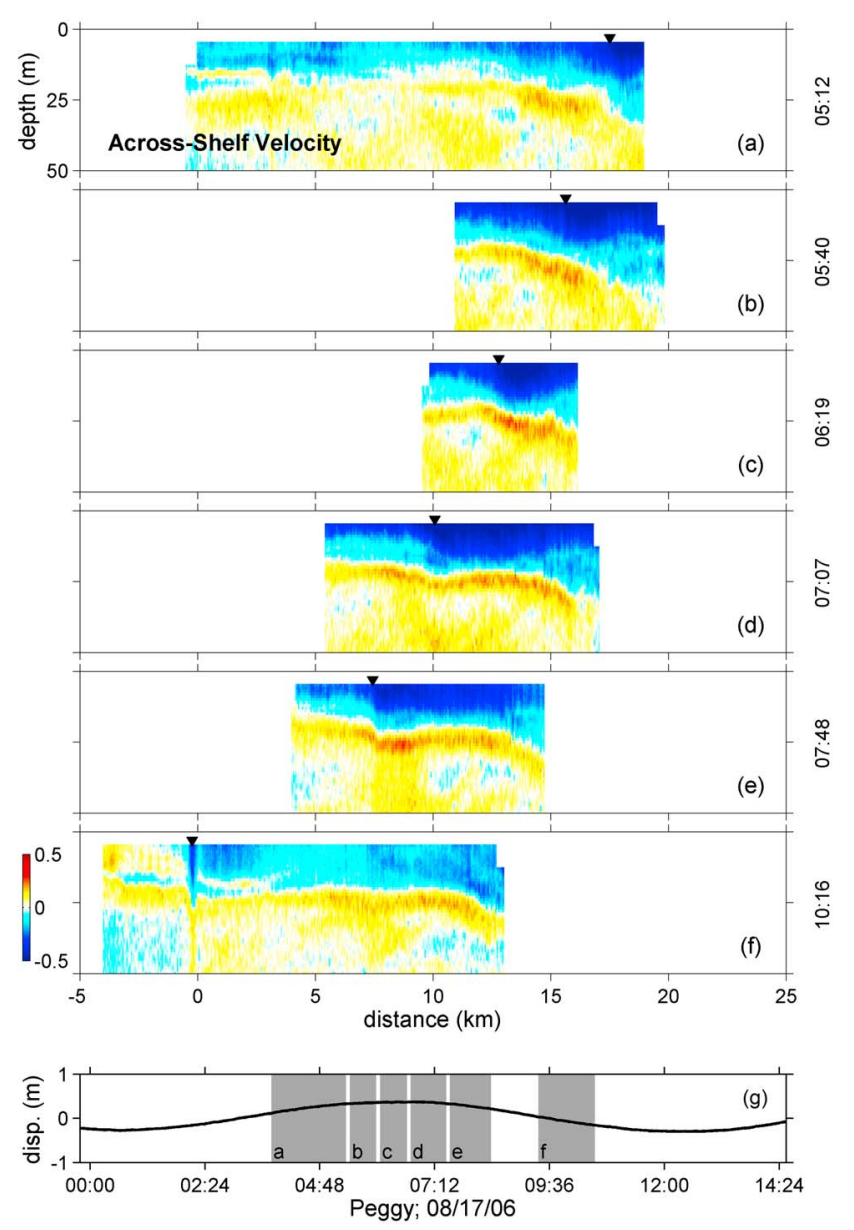

Figure 11. (a-f) Transects of across-shelf, baroclinic velocity plotted as a function of distance for Peggy B. Triangles at top mark the location of the leading edge of the tidal bore, qualitatively chosen from velocity and backscatter (not shown) fields. (g) The $\mathrm{M}_{2}$ tidal height at SW30 (0 km). Time periods of transects are shaded in grey.

semidiurnal tide. Despite the lack of predictability, the development of NLIWs from the internal tide was captured by several sets of ship observations (Figure 11). As an example, the tidal bore, Peggy B, was first transited near 0510 UTC 17 August 2006 (Figure 11a). The front traveled at $1 \mathrm{~m} \mathrm{~s}^{-1}$ shoreward and was tracked for approximately $3 \mathrm{~h}$ as the front edge steepened (e.g., Figures 11d and 11e), after which a leading NLIW emerged from the front in between $0-5 \mathrm{~km}$ as the barotropic tide ebbed. Phase speeds, calculated by differencing time and locations indicated by black triangles, decreased from $1 \mathrm{~m} \mathrm{~s}^{-1}$ to $0.9 \mathrm{~m} \mathrm{~s}^{-1}$ between Figure 11e and 11f. Note that a second wave packet (Peggy A) is also visible in Figure 11a. This packet led Peggy B by approximately $6 \mathrm{~h}$ and displayed a similar propagation direction $\left(300^{\circ}\right)$. Wave Sonny was also tracked from an early stage and reveals a similar story to that detailed above for Peggy B. Both Peggy B and Sonny occurred near the start of the period characterized by NLIW arrival times that were phased with $u_{M 2}$. The generation of these two packets seems to conform to the perhaps more common, and well-studied problem of NLIW evolution from a linear internal tide [Lee and Beardsley, 1974; Holloway, 1987; Smyth and Holloway, 1988; Holloway et al., 1997; Scotti et al., 2007] and supports the generation process proposed by Apel et al. [1997] for NLIWs observed during the SWARM experiment on the New Jersey shelf.

\subsection{A More Complicated Scenario}

[32] Observations of another wave group, Florence, show a more elaborate, convoluted example of wave formation (Figure 12). In this case, there is not a well-defined, mode 1 internal tide from which the NLIWs emerge. Instead, a wave group forms from a subsurface onshore pulse first observed at $10 \mathrm{~km}$ in the beginning of the flood tidal phase, further offshore than the formation location of Peggy B and at a different phase of the barotropic tide. As in the previous example, the first transect clearly shows a wave group preceding Florence by approximately $6 \mathrm{~h}$ (Figure 12 (right panels) at $-6 \mathrm{~km}$ ), which also propagated in the same direction as Florence at $300^{\circ}$. While these observations were recorded earlier in the month than those discussed above for Peggy B, both series show the generation of multiple wave packets per $\mathrm{M}_{2}$ tidal cycle. From the data shown in Figure 12 it is not clear that Florence's formation can be attributed to the steepening internal tide. The complexity of the background shear, which shows a higher mode structure, may play an important role in this formation story. The beam-like structure in the subsurface $(10-60 \mathrm{~m})$ velocity record observed between $10-21 \mathrm{~km}$ hints that scattering may be important for this wave.

[33] The relatively simple picture of the steepening of the incoming internal tide does not account for differences in wave formation between Peggy B and Florence, and it does not address the formation of multiple wave packets per tidal cycle. Given the vertical structure apparent in Figure 12, it seems necessary that any model of this formation process needs to allow for a multimodal structure. For example, a simple evolution based on the $\mathrm{KdV}$ or $\mathrm{eKdV}$ equations would not be appropriate, as modal structure is selected a priori in these cases. Preliminary efforts with a fully nonlinear, three-dimensional model, which is forced only by the $\mathrm{M}_{2}$ barotropic tide, have shown that multiple packets per tidal cycle sometimes emerge from a canyon to the south of the SW06 study site (A. Scotti, personal communication, 2010). The formation of multiple packets per tidal cycle would explain a large portion of the arrival time variability, particularly during certain periods when two wave groups per $\mathrm{M}_{2}$ tidal cycle were observed, e.g., 1-2 August and 13-14 August in Figure 8.

\subsection{Internal Tide and NLIW Modulation by Inertial Motions}

[34] Since both the arrival times and amplitudes of the NLIWs observed during 17-21 August were noteworthy (i.e., large and regularly spaced), we examine the mooring records of across-shelf velocity during this time period in greater detail (Figure 13).Note the well-behaved nature of the internal tide in that onshore/offshore pulses occur roughly twice a day. But curiously, strong onshore pulses at the shelf break (Figure 13a) did not always result in strong onshore velocity pulses or large NLIWs on the shelf (Figures 13b, 13c, and 13e). For example, consider the near- 

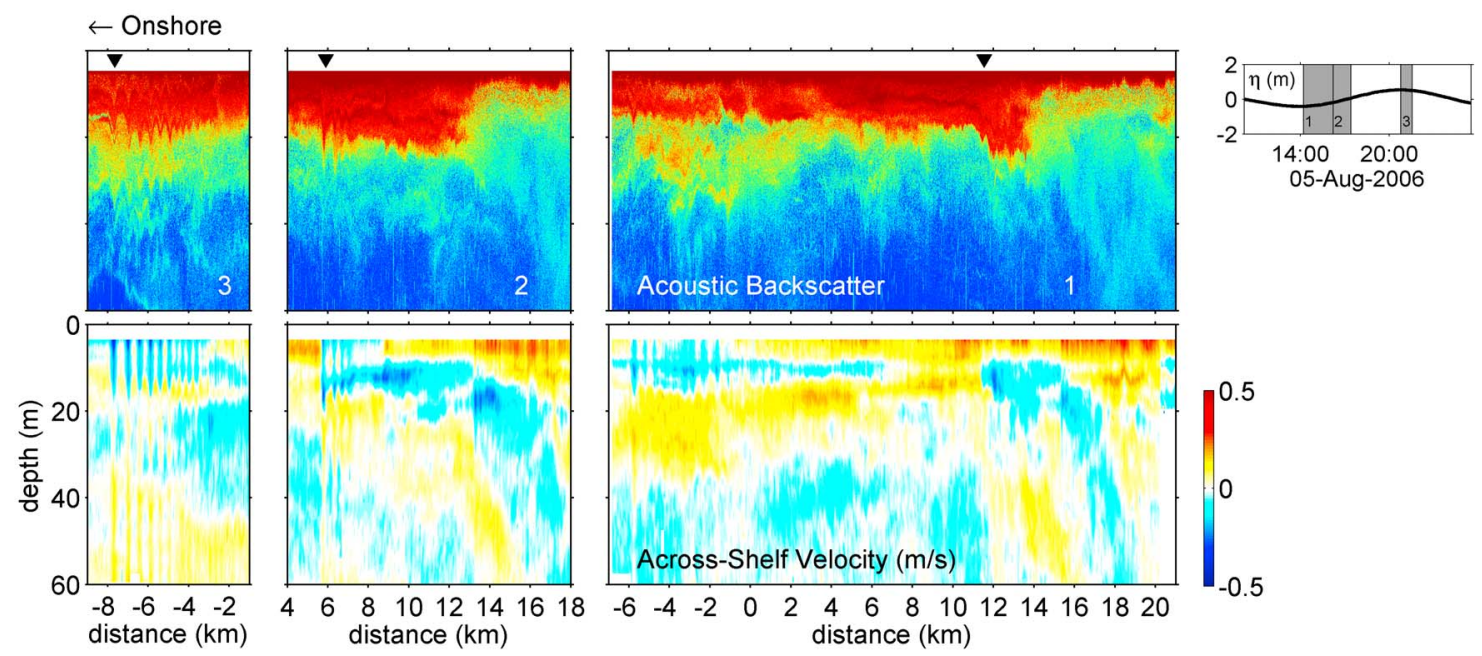

Figure 12. Transects of (top) acoustic backscatter and (bottom) across-shelf baroclinic velocity through Wave Florence on 5 August 2006. In time, the first transect is on the far right and the final transect is on the far left. Tidal height at SW30 is plotted in the top right, and transects are shaded in grey. Only the upper $60 \mathrm{~m}$ is plotted, but the actual depth varies from roughly $60 \mathrm{~m}$ onshore to greater than $80 \mathrm{~m}$ offshore. Triangles at top highlight location of leading wave qualitatively estimated from backscatter and velocity data.

surface, onshore pulses that are labeled in red in Figure 13a. Following the corresponding arrows through the mooring array, we find that the resultant onshore pulses at the outer shelf and midshelf mooring were reduced in duration and magnitude (Figures 13b and 13c). The opposite effect was also apparent with relatively weak, onshore pulses at the shelf break resulting in strong pulses on the shelf (refer to waves labeled in blue).

[35] Recall from section 3.2 that during this period the energy in near-inertial motions was of the same magnitude as the $\mathrm{M}_{2}$ internal tide (particularly at shelf moorings). A closer inspection of Figure 4 shows that while the $\mathrm{M}_{2}$ tide propagated across the shelf, inertial motions were relatively coherent. In the following, we suggest that the phasing of these two components, one of which was essentially a function only of time (inertial) and the other which depended on location as well as time $\left(\mathrm{M}_{2}\right)$, could account for the modulation of the onshore velocity pulses apparent in Figures 13a-13c. Furthermore, we hypothesize that the development of NLIWs may have been impacted by variability in background shear associated with the phasing of the near-inertial and $\mathrm{M}_{2}$ fields. Though beyond the scope of this paper, we emphasize that a modeling study is needed to lend further support to the analysis presented below.

[36] In order to understand this response, we proceed by first considering the superposition of the $\mathrm{M}_{2}$ and inertial fields, and we will attempt to address the influence on the formation of NLIWs afterward. The relative phasing of the near-surface $\mathrm{M}_{2}$ and the inertial series at SW30 is quantified by the normalized product,

$$
\Phi \equiv \frac{u_{M 2} \times u_{f}}{\max \left(u_{M 2} \times u_{f}\right)},
$$

where only regions in which near-surface $u_{M 2}<0$ (i.e., the incoming internal tide) are plotted in Figure 13d. When $\Phi$ is positive (blue) the two series constructively interfere; the opposite is true when $\Phi$ is negative (red). In general, weak pulses that turned into strong pulses (and large internal waves) correspond to $\Phi>0$, while strong pulses that became weaker on the shelf correspond to $\Phi<0$.

[37] Distance-time plots of near-surface, across-shelf velocity components, $u_{M 2}, u_{f}$, and $u_{f}+u_{M 2}$, are shown in Figure $14 \mathrm{a}-14 \mathrm{c}$ for mooring data. Note that in this section $u_{M 2}$ and $u_{f}$ refer to the near-surface averages and not to the full depth fields. Harmonic fits (section 3.2) were averaged between 10-25 $\mathrm{m}$ depth and interpolated across the shelf between moorings: SW30, SW62, and SW42. (These moorings are the same as those used to compile Figures 13a-13c.) $u_{M 2}$ was interpolated linearly along $\mathrm{M}_{2}$ characteristics defined using a polynomial fit to $c_{0}$ calculated from density data acquired across the slope and shelf, and $u_{f}$ was linearly interpolated across the shelf between SW30, SW62, and SW42. Figures $14 \mathrm{e}-14 \mathrm{~g}$ show time series created using a propagating, $\mathrm{M}_{2}$ wave of the form $u_{M 2}=a_{M 2} \sin \left(\omega_{M 2} x / \overline{c_{0}}+\right.$ $\left.\omega_{M 2} t+\phi_{M 2}\right)$ and an inertial wave, $u_{f}=a_{f} \sin \left(\omega_{f} t+\phi_{f}\right)$, with no spatial dependence. The amplitudes $\left(a_{i}\right)$ and phases $\left(\phi_{i}\right)$ were selected to agree qualitatively with observed time series; a constant phase speed was assumed for the modeled $\mathrm{M}_{2}$ wave. Although the parameters of these linear models are arbitrary, the comparison is made to emphasize the agreement between the observations, which depend on the harmonic fits of the time series, and the modeled waves that are inherently simple in nature.

[38] The time required for the $\mathrm{M}_{2}$ wave to propagate from the shelf break to SW30 was slightly over $6 \mathrm{~h}$, corresponding to approximately half of the $\mathrm{M}_{2}$ tidal period and a third of the inertial period. As a result, the phasing between $u_{M 2}$ and $u_{f}$ at the slope mooring differs from the phasing of the two signals on the shelf. For waves B, D, E, G, H, and K (i.e., blue waves), near-surface $u_{f}$ was directed offshore, opposing $u_{M 2}$, at the shelf break. The two signals were thus out of phase, and the combination of $u_{M 2}$ and $u_{f}$ produced a smaller onshore velocity pulse at the shelf break. However, 
a)

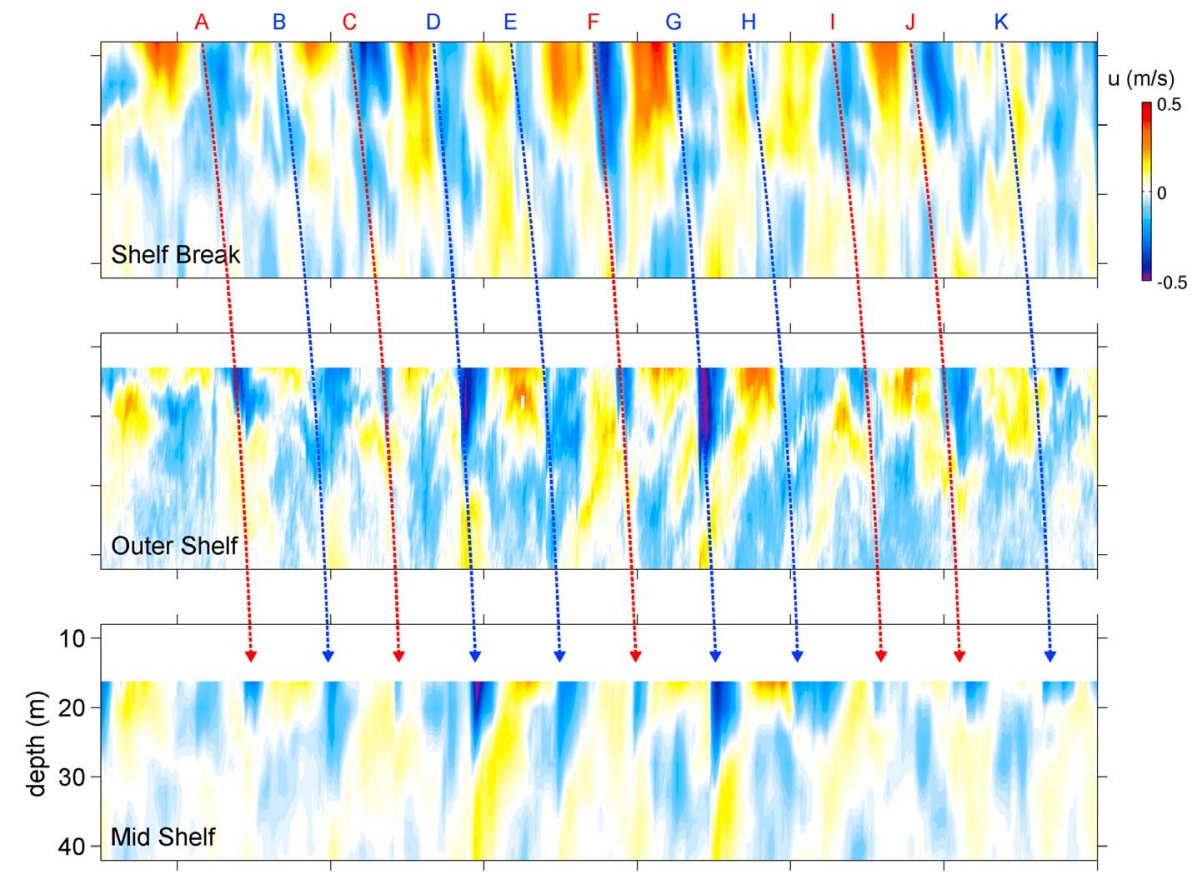

d)

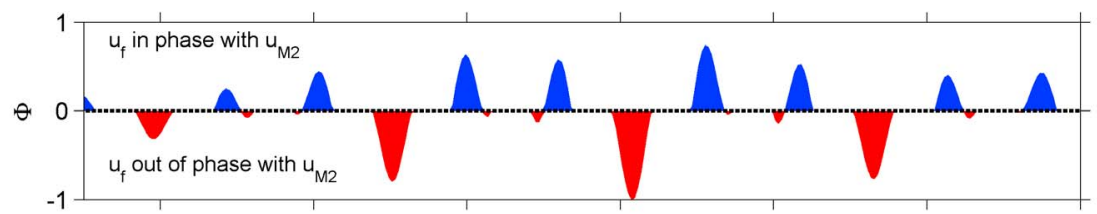

e)

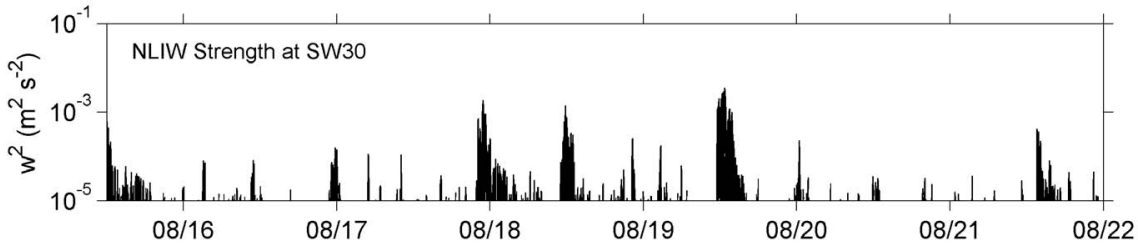

Figure 13. Across-shelf baroclinic velocity (30 min bin averages) at (a) SW42, (b) SW62, and (c) SW30 for the period of large waves. Onshore $\mathrm{M}_{2}$ pulses are tracked through the mooring line with the dashed arrows; colors (blue/red) are used to distinguish between pulses that increased/decreased in strength as the tide propagated onshore. (d) The interference of the $\mathrm{M}_{2}$ tide and inertial waves at SW30. (e) The square of the depth-mean vertical velocity at SW30 $\left(w^{2}\right)$, which is a proxy for NLIW energy.

on the shelf the $u_{M 2}$ and $u_{f}$ were in phase (Figure $13 \mathrm{~d}$ and Figure 14b), producing a larger onshore velocity pulse. The reverse was true for waves $\mathrm{C}, \mathrm{F}$, and I (i.e., red waves). For these waves, $u_{f}$ was directed onshore at the shelf break, constructively interfering with $u_{M 2}$ creating a large, onshore pulse, and $u_{f}$ was directed offshore on the shelf, adding to produce a smaller onshore pulse. Waves $\mathrm{A}$ and $\mathrm{J}$ do not fit the pattern as well, although we note that while these waves are designated red the magnitudes of the near-surface, onshore pulses did not change much between the slope and shelf.

[39] The strong beating evident in Figure 14c results partially because of the relation between the $\mathrm{M}_{2}$ tidal period and the inertial period at this latitude, $3 \tau_{M 2} \sim 2 \tau_{f}$, producing a pattern that repeats roughly every $37 \mathrm{~h}$. The pattern created by the superposition of $u_{f}$ and $u_{M 2}$ is highlighted further in Figure $14 \mathrm{~g}$, which emphasizes the beating pattern that would be created if two idealized linear waves were added. The phasing between $u_{f}$ and $u_{M 2}$ at the shelf break is summarized in Figures $14 \mathrm{~d}$ and $14 \mathrm{~h}$. Arrival times of the $\mathrm{M}_{2}$ baroclinic tide at $18 \mathrm{~km}$ (colored circles, Figures 14d and 14h) are plotted over the across-shelf average of nearsurface $u_{f}$. Figures $14 \mathrm{~d}$ and $14 \mathrm{~h}$ are intended to emphasize the phase pattern, in which one onshore, $\mathrm{M}_{2}$ pulse occurs near peak onshore $u_{f}$ (red circles) followed by a series of two $\mathrm{M}_{2}$ pulses occurring slightly offset from peak offshore $u_{f}$ (blue circles).

[40] While the simple addition of linear, $u_{f}$ and $u_{M 2}$ seems to explain the across-shelf variation in the magnitude of the onshore pulses observed in Figure 13, the effect on the NLIW field is perhaps more difficult to understand. Specifically, why did larger-amplitude waves tend to form when $u_{f}$ was in phase with $u_{M 2}$ at SW30 (Figures 13d and $13 \mathrm{e})$ ? One possible explanation is that near-inertial 

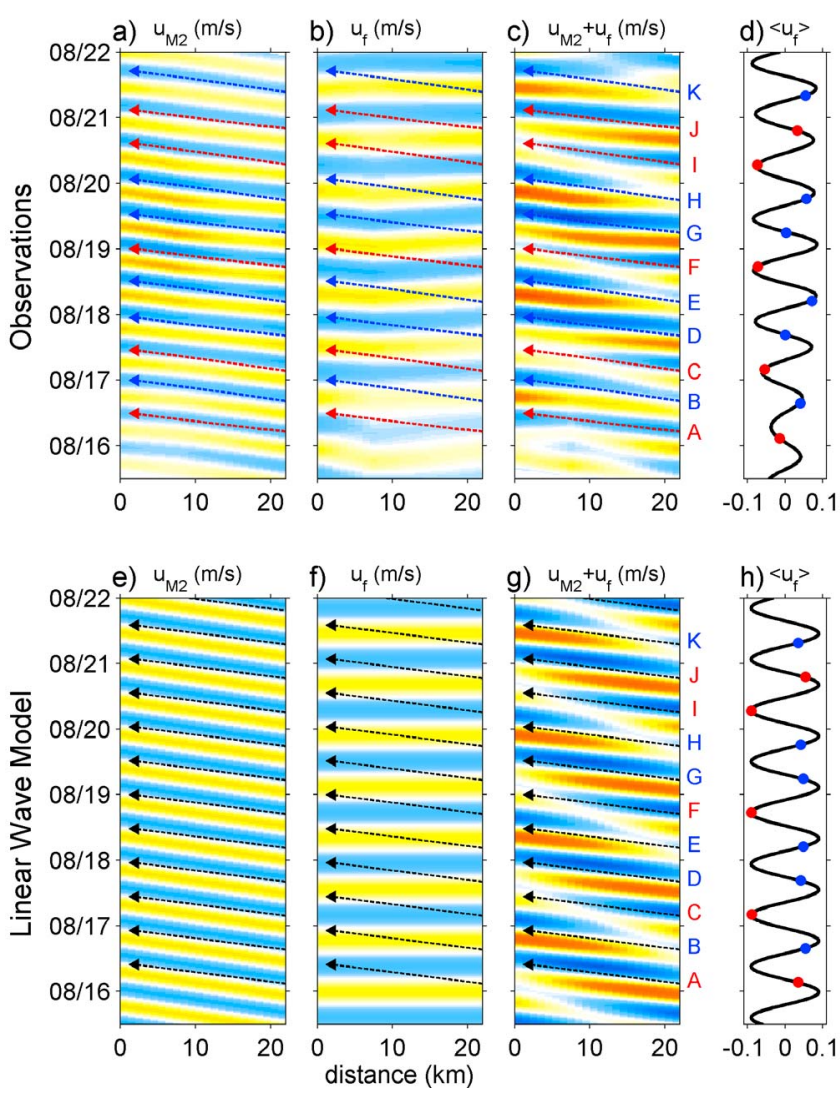

Figure 14. Distance-time plots of near-surface, acrossshelf velocity components, (a, e) $u_{M 2}$, (b, f) $u_{f}$, and (c, g) $u_{f}+u_{M 2}$ for observed, harmonic series (Figures $14 \mathrm{a}-$ 14c) and modeled, linear waves (Figures 14e-14g). Waves A-K (Figure 13) are traced across the shelf (Figures 14c and $14 \mathrm{~g}$ ) and are color coded in accordance with Figure 13. (d, h) The across-shelf averages of near-surface $u_{f}$. Colored circles correspond to the arrival times of the onshore phase of the $\mathrm{M}_{2}$ tide at $18 \mathrm{~km}$.

shear on the outer shelf and slope influences the coefficient of nonlinearity, $\alpha$, and hence will effect tidal steepening and consequent NLIW formation. As previously mentioned, the time required for an $\mathrm{M}_{2}$ wave to propagate between the shelf break and SW30 ( $>6 \mathrm{~h})$ is a significant portion of both the $\mathrm{M}_{2}$ and inertial period. As such, the near-inertial shear changed significantly between the slope and the shelf, and waves associated with a positive/negative $\Phi$ at SW30 were associated with a negative/positive $\Phi$ near the shelf break. For waves color coded blue in Figures 13 and 14, the inertial shear on the outer shelf/slope was positive (i.e., the upper layer opposed the direction of wave propagation). Positive shear decreases $\alpha$, thus increasing nonlinearity. (That is, $\alpha$ becomes more negative.) Linear, tidal steepening would happen earlier for these waves, and as a result we would expect to see larger-amplitude NLIWs at SW30. The opposite is true for negative inertial shear near the shelf break, which was present for most red waves. In this case, nonlinearity is decreased as $\alpha$ becomes less negative, and shock formation would be delayed.

[41] Although this explanation seems reasonable, it is surprising that the near-inertial field could provide a back- ground state for the internal tide. Even though the nearinertial period is long compared to the time scale of the NLIWs, it is not long in comparison to the $\mathrm{M}_{2}$ period. However, perhaps a more relevant time scale is that between the inertial period and that necessary for steepening of the internal tide and NLIW formation, which as previously stated is roughly $6 \mathrm{~h}$. It seems reasonable to expect that a reversal of mode 1 shear, related to inertial motions, should effect the steepening of the tide over this time scale. Again, we emphasize that further analysis, including a modeling component, is needed to understand how or if relatively high-frequency variability in the background state may effect NLIW formation from the internal tide.

\section{Summary}

[42] During the Shallow Water 2006 experiment on New Jersey's continental shelf, nonlinear internal waves experienced a highly variable environment and were influenced by a variety of field and forcing conditions, including mesoscale shifts in stratification at the shelf break, changing wind conditions, and energetic near-inertial shear. The resultant NLIWs were characterized by two regimes. Over a large portion of the month, NLIW amplitudes were on average $-8 \mathrm{~m}$ with wave arrival times at a given location occurring irregularly with respect to the barotropic tide. However, from approximately 17-22 August, NLIW displacements exceeded $15 \mathrm{~m}$, and during this same period, wave arrival times were more clearly phased with the barotropic tide. This time period was also characterized by a shift in the background conditions, in which the location of the shelfbreak front moved shoreward and near-inertial energy increased over the shelf. Work by Nash et al. (manuscript in preparation, 2011) suggests that while the consequent shift in the mesoscale stratification at the shelf break played a role in increasing tidal flux on the shelf, the magnitude of the increase in the observed shoreward energy flux cannot be completely accounted for by considering local generation alone; and hence, remotely shoaling waves likely play an important role in setting the internal tide (and consequently the NLIW field) on the shelf.

[43] NLIW formation from the larger scale tidal flow was documented for two wave groups. In one case, formation seems to be relatively straightforward with waves developing as the mode 1 baroclinic tidal front first steepened and then dispersed into a wave group. However, the second example, which was characterized by a highly sheared background state, is not straightforward to interpret. In this case, NLIWs emerged from a subsurface, onshore velocity pulse, differing from a mode 1 internal tide. In both cases, there is evidence that NLIWs were created at $\sim 6 \mathrm{~h}$ intervals as opposed to only once a semidiurnal tidal period. During the time period of large-amplitude waves and strong nearinertial energy, the incoming internal tide was apparently modulated by inertial motions. When the tide was out of phase with the inertial field on the slope, initially weak, onshore pulses at the shelf break were stronger on the shelf and were accompanied by larger NLIWs. The reverse was true when the $\mathrm{M}_{2}$ internal tide was in phase with the nearinertial velocity on the slope. In such cases, onshore tidal pulses were strong at the shelf break, but weak onshore. The corresponding NLIWs were also reduced in energy. 
[44] A shortcoming of this paper is that the influence of three-dimensional effects on background conditions and the NLIW field is not addressed. Temporal and spatial variability in frontal meanders may influence the focusing of wave energy, as well as the location of generation regions. Complex topography, including a canyon to the south of the study site, undoubtedly effect that generation of the local internal tide and accordingly the NLIW field. The interference of multiple wave groups with one another and the presence of localized topographic features (e.g., the small rise mentioned in regards to Figure 6) will influence the three-dimensionality of the shoaling NLIWs. Indeed, remote imagery capturing the spatial variability of the New Jersey NLIW field suggests three-dimensionality may be highly important in this region. This qualitative assessment agrees with data series observed from an additional SW06 mooring (not mentioned previously) located in the along-shore branch of the mooring array. This record shows that in some waves significant variability is observed at less than the $10 \mathrm{~km}$ scale in the along-crest direction. This topic needs further exploration and should be addressed in a future study, possibly either numerical or observational in nature.

[45] The variability in the New Jersey NLIW field, which was expressed not only in the character (e.g., amplitude and arrival times) of the waves but also in wave formation and shoaling, was remarkable. For example, consider the polarity conversion (depression to elevation) of some wave groups (albeit all large-amplitude waves) that was observed at the locations where $\alpha>0$ (Figure 6c), while for other groups depression waves continued to persist inshore for 10 s of kilometers. Such details suggest that the applicability of modeling studies initialized with climatology, or highly averaged data, must to some extent be limited when considering wave evolution, since the time and space scales that influence the NLIWs are not well represented by long-term averages. In addition, considering the range of wave amplitudes, it is not surprising that the transports and mixing associated with the NLIWs also differ amongst individual wave groups [Shroyer et al., 2010c]. Given the variability observed in just one month, it would be interesting to document the internal tide and NLIW field over a longer time period (possibly an entire spring/summer or over multiple years). Such an effort may help determine which processes control the character of the internal tide and NLIWs and whether/how these processes vary in time and space.

\section{Appendix A: Harmonic Decomposition}

[46] Velocity time series were first averaged into $30 \mathrm{~min}$ bins, then decomposed at each depth using

$$
u(t)=u_{0}+\sum_{i=1}^{3} a_{i} \cos \left(2 \pi \omega_{i} t\right)+b_{i} \sin \left(2 \pi \omega_{i} t\right)+u_{r}
$$

where $\omega_{1-3}$ were composed of $\mathrm{M}_{2}, \mathrm{~K}_{1}$ and near-inertial frequencies $(f)$. The coefficients $a_{i}$ and $b_{i}$ were solved for by minimizing the variance of the velocity residual, $u_{r}$, via least squares analysis. The above expression was applied over a 6 day running interval shifted temporally every half hour. Overlapping bins were averaged together. The 6 day running average imposed in the decomposition effectively filters the baroclinic field, $u_{0}$, for fluctuations less than $\sim 10$ days. Barotropic components were assumed to be equivalent to depth-averaged quantities [Kelly et al., 2010], and baroclinic fields (Figure 4) were calculated by subtracting the depth mean. NLIW packets undoubtedly have some effect on the harmonic decomposition; however, due to the sporadic arrival times at moorings, the wave influence may not be as severe as might be expected in other regions such as the South China Sea [Duda et al., 2004]. The vertical structure of internal motions (Figure 5) was investigated using empirical orthogonal functions (E.O.F.s), which were computed for $u_{f}, u_{K 1}$, and $u_{M 2}$ using the fields shown in Figures $4 \mathrm{c}-4 \mathrm{e}$.

[47] Acknowledgments. This work was funded by the Office of Naval Research. We thank the Captains and crews of the R/V Oceanus, which performed the tracking experiment, and the R/V Knorr, which deployed and recovered moorings. Mike Neeley-Brown, Ray Kreth, Alexander Perlin, Greg Avicola, and Sam Kelly helped obtain the data during the wave tracking experiment. John Kemp, James Lynch, and James Irish were responsible for the mooring deployment and recovery. We also thank Glen Gawarkiewicz and Craig Marquette for the SW62 mooring data.

\section{References}

Alpers, W. (1985), Theory of radar imaging internal waves, Nature, 314, 245-247.

Apel, J., H. Byrne, J. Proni, and R. Charnell (1975), Observations of oceanic internal and surface waves from the Earth Resources Technology Satellite, J. Geophys. Res., 80, 865-881.

Apel, J. R., J. R. Holbrook, A. K. Liu, and J. J. Tsai (1985), The Sulu Sea Internal Soliton Experiment, J. Phys. Oceangr., 15, 1625-1651.

Apel, J. R., et al. (1997), An overview of the 1995 SWARM shallow-water internal wave acoustic scattering experiment, J. Oceanic Engin., 22, 465-500.

Chapman, D., J. Barth, R. Beardsley, and R. Fairbanks (1986), On the continuity of mean flow between the Scotian Shelf and the Middle Atlantic Bight, J. Phys. Oceangr., 16, 758-772.

Chereskin, T. K. (1983), Generation of internal waves in Massachusetts Bay, J. Geophys. Res., 88, 2649-2661.

Colosi, J. A., R. C. Beardsley, J. F. Lynch, G. Gawarkiewicz, C.-S. Chiu, and A. Scotti (2001), Observations of nonlinear internal waves on the outer New England continental shelf during the summer Shelfbreak Primer study, J. Geophys. Res., 106, 9587-9601.

Duda, T. F., J. F. Lynch, J. D. Irish, R. C. Beardsley, S. R. Ramp, C.-S. Chiu, T. Y. Tang, and Y.-J. Yang (2004), Internal tide and nonlinear internal wave behavior at the continental slope in the northern South China Sea, IEEE J. Oceanic Eng., 29, 1105-1130.

Egbert, G. D., A. Bennett, and M. Foreman (1994), TOPEX/Poseidon tides estimated using a global inverse model, J. Geophys. Res., 99, 24,821-24,852

Fratantoni, P., R. Pickart, D. Torres, and A. Scotti (2001), Mean structure and dynamics of the shelfbreak jet in the Middle Atlantic Bight during Fall and Winter, J. Phys. Oceangr., 31, 2135-2156.

Gasparovic, R., J. Apel, and E. Kasischke (1988), An overview of the SAR Internal Wave Signature Experiment, J. Geophys. Res., 93, 12,304-12,316.

Gerkema, T. (2001), Internal and interfacial tides: Beam scattering and local generation of solitary waves, J. Mar. Res., 59, 227-255.

Grimshaw, R., E. Pelinovsky, T. Talipova, and A. Kurkin (2004), Simulation of the transformation of internal solitary waves on oceanic shelves, J. Phys. Oceangr., 34, 2774-2791.

Haury, L. R., M. G. Briscoe, and M. H. Orr (1979), Tidally generated internal wave packets in Massachusetts Bay, Nature, 278, 312-317.

Holloway, P. E. (1987), Internal hydraulic jumps and solitons at a shelf break region on the Australian North West Shelf, J. Geophys. Res., 92, 5405-5416.

Holloway, P. E., E. Pelinovsky, T. Talipova, and B. Barnes (1997), A nonlinear model of internal tide transformation on the Australian North West Shelf, J. Phys. Oceangr., 27, 871-896.

Inall, M. E., T. P. Rippeth, and T. J. Sherwin (2000), Impact of nonlinear waves on the dissipation of the internal tidal energy at a shelf break, J. Geophys. Res., 105, 8687-8705.

Jackson, C. R. (2004), An Atlas of Internal Solitary-like Waves and Their Properties, 2nd ed., Global Ocean Assoc., Alexandria, Va. (Available at http://www.internalwaveatlas.com.) 
Jeans, D. R. G., and T. J. Sherwin (2001), The variability of strongly nonlinear solitary internal waves observed during an upwelling season on the Portuguese shelf, Cont. Shelf Res., 21, 1855-1878.

Kelly, S. M., J. D. Nash, and E. Kunze (2010), Internal-tide energy over topography, J. Geophys. Res., 115, C06014, doi:10.1029/2009JC005618.

Klymak, J. M., R. Pinkel, C.-T. Liu, A. K. Liu, and L. David (2006), Prototypical solitons in the South China Sea, Geophys. Res. Lett., 33, L11607, doi:10.1029/2006GL025932.

Lamb, K. G., and B. Wang (1998), Conjugate flows and flat solitary waves for a continuously stratified fluid, Phys. Fluids, 10, 2061-2079.

Lee, C.-Y., and R. C. Beardsley (1974), The generation of long nonlinear internal waves in a weakly stratified shear flow, J. Geophys. Res., 79, 453-462.

Linder, C. A., and G. Gawarkiewicz (1998), A climatology of the shelfbreak front in the Middle Atlantic Bight, J. Geophys. Res., 103, $18,405-18,423$.

Liu, A. K., Y. S. Chang, M.-K. Hsu, and N. K. Liang (1998), Evolution of nonlinear internal waves in the East and South China Seas, J. Geophys. Res., 103, 7995-8008.

Liu, A. K., Y. Zhao, T. Y. Tang, and S. R. Ramp (2004), Model-data assimilation of internal waves in ASIAEX 2001, IEEE J. Oceanic Eng., 29, 1144-1156.

MacKinnon, J. A., and M. C. Gregg (2003), Mixing on the late-summer New England shelf - solibores, shear and stratification, J. Phys. Oceangr., 33, 1476-1492.

Moody, J., and B. Butman (1984), American Continental Shelf, U.S. Geol. Surv. Bulletin 1611.

Moum, J. N., and J. D. Nash (2008), Seafloor pressure measurements of nonlinear internal waves, J. Phys. Oceangr., 38, 481-491.

Moum, J. N., M. C. Gregg, R. C. Lien, and M. E. Carr (1995), Comparison of turbulence kinetic energy dissipation rate estimates from two ocean microstructure profilers, J. Atmos. Oceanic Technol., 12, 346-366.

Moum, J. N., D. M. Farmer, W. D. Smyth, L. Armi, and S. Vagle (2003), Structure and generation of turbulence at interfaces strained by internal solitary waves propagating shoreward over the continental shelf, J. Phys. Oceangr., 33, 2093-2112.

Moum, J., J. Klymak, J. Nash, A. Perlin, and W. Smyth (2007), Energy transport by nonlinear internal waves, J. Phys. Oceangr., 37, 1968-1988.

New, A. L., and R. D. Pingree (1990), Large-amplitude internal soliton packets in the central Bay of Biscay, Deep Sea Res., Part A, 37, 513-524.

New, A. L., and R. D. Pingree (1992), Local generation of internal soliton packets in the central bay of Biscay, Deep Sea Res., Part A, 39, 15211534.

Orr, M. H., and P. C. Mignerey (2003), Nonlinear internal waves in the South China Sea: Observation of the conversion of depression internal waves to elevation internal waves, J. Geophys. Res., 108(C3), 3064, doi:10.1029/2001JC001163.
Osborne, A. R., and T. L. Burch (1980), Internal solitons in the Adaman Sea, Science, 208, 451-460.

Perry, R., and G. Schimke (1965), Large amplitude internal waves observed off the northwest coast of Sumatra, J. Geophys. Res., 70, 2319-2324.

Ramp, S. R., J. F. Lynch, P. H. Dahl, C. Chiu, and J. A. Simmen (2003), Program fosters advances in shallow-water acoustics in southeastern Asia, Eos Trans. $A G U, 84,361$.

Ramp, S. R., T.-Y. Tang, T. F. Duda, J. F. Lynch, A. K. Liu, C.-S. Chiu, F. Bahr, H.-R. Kim, and Y. J. Yang (2004), Internal solitons in the northern South China Sea, Part I: Sources and deep water propagation, IEEE J. Oceanic Eng., 29, 1157-1181.

Sandstrom, H., and J. A. Elliott (1984), Internal tide and solitons on the Scotian Shelf: A nutrient pump at work, J. Geophys. Res., 89, 6415-6426.

Sandstrom, H., and N. S. Oakey (1994), Dissipation of internal tides and solitary waves, J. Phys. Oceangr., 25, 604-614.

Scotti, A., R. C. Beardsley, and B. Butman (2007), Generation and propagation of nonlinear internal waves in Massachusetts Bay, J. Geophys. Res., 112, C10001, doi:10.1029/2007JC004313.

Shroyer, E., J. Moum, and J. Nash (2009), Observations of polarity reversal in shoaling nonlinear internal waves, J. Phys. Oceangr., 39, 691-701.

Shroyer, E. L., J. N. Moum, and J. D. Nash (2010a), Mode 2 waves on the continental shelf: Ephemeral components of the nonlinear internal wavefield, J. Geophys. Res., 115, C07001, doi:10.1029/2009JC005605.

Shroyer, E., J. Moum, and J. Nash (2010b), Energy transformations and dissipation of nonlinear internal waves over New Jersey's continental shelf, Nonlinear Processes Geophys., 17, 345-360.

Shroyer, E. L., J. N. Moum, and J. D. Nash (2010c), Vertical heat flux and lateral mass transport in nonlinear internal waves, Geophys. Res. Lett. 37, L08601, doi:10.1029/2010GL042715.

Small, J., T. C. Sawyer, and J. C. Scott (1999), The evolution of an internal bore at the Malin shelf break, Ann. Geophys., 17, 547-565.

Smyth, N. F., and P. E. Holloway (1988), Hydraulic jump and undular bore form on a shelf break, J. Phys. Oceangr., 18, 947-962.

Stanton, T. P., and L. A. Ostrovsky (1998), Observations of highly nonlinear internal solitons over the continental shelf, Geophys. Res. Lett., 25, 2695-2698.

Stastna, M., and K. Lamb (2002), Large fully nonlinear internal solitary waves: The effect of background current, Phys. Fluids, 14, 2987-2999. Tang, D. J., et al. (2007), Shallow Water '06, Oceanography, 20, 156-167.

J. N. Moum and J. D. Nash, College of Oceanic and Atmospheric Sciences, Oregon State University, 104 Ocean Admin. Bldg., Corvallis, OR 97331-5503, USA.

E. L. Shroyer, Woods Hole Oceanographic Institution, Clark 316A, MS21, Woods Hole, MA 02543, USA. (eshroyer@whoi.edu) 